\title{
Characterization of Fault Zones
}

\author{
Yehuda Ben-Zion ${ }^{1}$ and Charles G. SAmmis ${ }^{1}$
}

\begin{abstract}
There are currently three major competing views on the essential geometrical, mechanical, and mathematical nature of faults. The standard view is that faults are (possibly segmented and heterogeneous) Euclidean zones in a continuum solid. The continuum-Euclidean view is supported by seismic, gravity, and electromagnetic imaging studies; by successful modeling of observed seismic radiation, geodetic data, and changes in seismicity patterns; by detailed field studies of earthquake rupture zones and exhumed faults; and by recent high resolution hypocenter distributions along several faults. The second view focuses on granular aspects of fault structures and deformation fields. The granular view is supported by observations of rock particles in fault zone gouge; by studies of block rotations and the mosaic structure of the lithosphere (which includes the overall geometry of plate tectonics); by concentration of deformation signals along block boundaries; by correlation of seismicity patterns on scales several times larger than those compatible with a continuum framework; and by strongly heterogeneous wave propagation effects on the earth's surface. The third view is that faults are fractal objects with rough surfaces and branching geometry. The fractal view is supported by some statistical analysis of regional hypocenter locations; by long-range correlation of various measurements in geophysical boreholes; by the fact that observed power-law statistics of earthquakes are compatible with an underlying scale-invariant geometrical structure; by geometrical analysis of fault traces at the earth's surface; and by measurements of joint and fault surfaces topography.

There are several overlaps between expected phenomenology in continuum-Euclidean, granular, and fractal frameworks of crustal deformation. As examples, highly heterogeneous seismic wavefields can be generated by granular media, by fractal structures, and by ground motion amplification around and scattering from an ensemble of Euclidean fault zones. A hierarchical granular structure may have fractal geometry. Power-law statistics of earthquakes can be generated by slip on one or more heterogeneous planar faults, by a fractal collection of faults, and by deformation of granular material. Each of the three frameworks can produce complex spatio-temporal patterns of earthquakes and faults. At present the existing data cannot distinguish unequivocally between the three different views on the nature of fault zones or determine their scale of relevance. However, in each observational category, the highest resolution results associated with mature large-displacement faults are compatible with the standard continuumEuclidean framework. This can be explained by a positive feedback mechanism associated with strain weakening rheology and localization, which attracts the long-term evolution of faults toward progressive regularization and Euclidean geometry. A negative feedback mechanism associated with strain hardening during initial deformation phases and around persisting geometrical irregularities and conjugate sets of faults generates new fractures and granularity at different scales. We conclude that long-term deformation in the crust, including many aspects of the observed spatio-temporal complexity of earthquakes and faults, may be explained to first order within the continuum-Euclidean framework.
\end{abstract}

Key words: Fault zone evolution, continuum-Euclidean, fractal, granular, complexity, simplicity.

${ }^{1}$ Department of Earth Sciences, University of Southern California, Los Angeles, CA 90089-0740, U.S.A. E-mails: benzion@terra.usc.edu, sammis@earth.usc.edu 


\section{Introduction}

Earthquakes are processes associated with objects that are called fault zones. Earthquake physics is thus dictated to a very large extent by fault zone properties. In this paper we review conceptual frameworks and data on the character and properties of earthquake fault zones, guided by the following three questions: 1) What are the geometrical properties of a fault zone? 2) What is the best theoretical framework to describe fault mechanics? 3) How do the answers depend on scale? Figure 1 illustrates the complexity involved in addressing these questions. On the global plate-tectonics scale, all of western California may be considered as a fault zone between the Pacific and North American plates. It appears granular in the sense of having crustal blocks that translate and rotate to accommodate the deformation. It contains several strands of localized deformation that form the major sub-parallel faults in the San Andreas system, bordered by a network of subsidiary faults with complex geometry. Focusing down in scale to the main trace of the San Andreas fault reveals a core of crushed rock containing multiple shear localizations, bordered by zones of intense fracturing and damaged rock. Numerous bends and jogs along the main strands tend to be sites of additional structural complexity. The California plate boundary may thus be viewed as a nested hierarchy of shear localizations within shear localizations, each surrounded by a granular or a continuum matrix. A fundamental question is whether this complex structure is self-similar geometrically and mechanically, or whether different frameworks are required at different scales. A related key issue is whether all components of the visible complex structure, or perhaps just a few or even one, play a dominant role in accommodating the long-term tectonic deformation.

As suggested by the foregoing description, the three major competing views on the essential geometrical, mechanical, and mathematical (GMM) nature of faults are continuum-Euclidean, granular, and fractal. Each of these frameworks carries a very different set of implications. In the first standard view, faults are collections of planar or tabular Euclidean zones in a continuum solid. In the continuum-Euclidean framework, the underlying "macroscopic" GMM structure is fundamentally smooth and continuous (e.g., FunG, 1977). This implies the possibility of stable or convergent averaging of abrupt fluctuations over smaller space-time scales that are referred to as "microscopic," and clear separation between the microscopic and macroscopic scales. The suitably averaged macroscopic description has gradual variations of all fields. Slip on Euclidean faults in a continuum solid can be analyzed in terms of fracture mechanics, friction, and other constitutive laws measured in laboratory rock-mechanics experiments. The constitutive laws, like all other functions, vary smoothly with the ongoing deformation. Stress transfer from a slip region falls in the far field like $1 / r^{3}$ with $r$ being the distance from the source. This provides an estimate for the size of expected correlation of stress and other dynamic variables in a continuum solid. In a medium governed by a strain weakening rheology, deformation processes and structures are expected to evolve toward the 


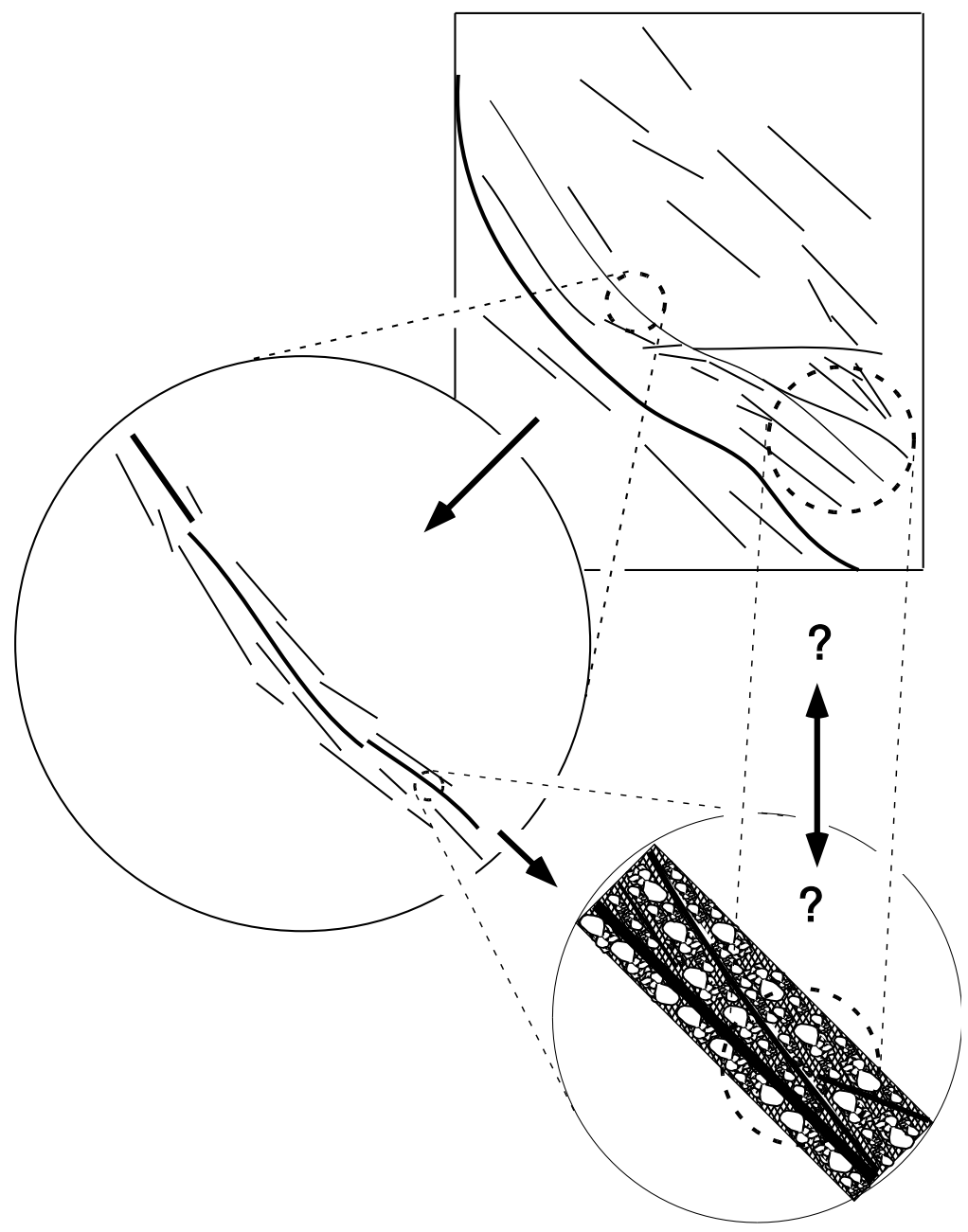

Figure 1

Schematic map views of fault structures at different scales, each with possible Euclidean, granular, and fractal geometrical features. At the largest scale containing boundary regions of different plates, shear is distributed over a network of faults. At a plate boundary scale, individual major faults in the network consist of a quasi-linear array of subparallel strands. At internal fault-zone scale, each strand consists of a distributed band of intense fracturing containing one or more tabular zones of strain localization and intense fragmentation. The arrows between the different scales suggest the possibility that the key structural elements repeat at different scales.

continuum-Euclidean framework. This is because strain weakening produces zones of localized deformation and strength reduction, leading to further strain localization and strength reduction. In an ideal homogeneous quasi-static case, this positive feedback mechanism cascades into deformation that is concentrated on a planar fault in a surrounding elastic continuum. In actual cases, heterogeneities of material 
properties and applied fields, dynamic branching, etc. produce complications that prevent complete localization. Nevertheless, the long-term deformation in a brittle solid governed by a strain weakening rheology will still be dominated by Euclidean structures of size comparable to that of the overall medium dimensions (e.g., depth of seismogenic zone), surrounded by a more-or-less continuum matrix that contains a variety of lesser structures.

The second view focuses on granular aspects of fault structures and deformation fields. In the granular framework, the fundamental GMM structure is discrete and strongly heterogeneous. Abrupt fluctuations of fields are present and cannot be averaged out. Load is supported mostly along a few "connectivity chains" rather than the whole medium, producing strong macroscopic anisotropy of all fields (e.g., JAEGER et al., 1996). As a consequence, correlation lengths of dynamic variables exhibit strong directivity effects. For example, stress transfer along the connectivity chains can decay much slower than $1 / r^{3}$, at the expense of much faster decay in other directions. While deformation of granular media includes strong fluctuations, it is still possible to use concepts from fracture mechanics and friction with appropriate modifications. In contrast to a continuum description, however, constitutive laws of granular material may vary abruptly at places. The granular framework is expected to hold in a medium governed by a strain hardening rheology that creates a negative feedback mechanism opposite to that associated with strain weakening. This leads to ongoing creation of new fractures, overall distributed or diffused deformation, and structures of relatively small size compared to the overall dimensions of the deforming domain.

The third view is that faults are fractal objects with rough surfaces and branching geometry. In the fractal framework, the fundamental GMM structure is irregular, discrete, and heterogeneous on all scales (e.g., MANDELBRot, 1983). If we take the fractal framework at face value, differential calculus and associated continuum-based concepts like stress, strain, fracture, and friction are not valid. At present there are no corresponding mathematical and mechanical quantities, or effective constitutive laws, to describe deformation in a solid with a truly fractal geometry. The fractal framework implies a dynamic balance between strain weakening and strain hardening processes that is perfectly or critically tuned to produce neither positive nor negative overall feedback during deformation. In such a case, the long-term deformation is accommodated by a collection of structures that have no preferred size scale, i.e., structures following a power-law frequency-size distribution. Fractal geometry has been reported to characterize brittle deformation structures in the crust over several bands of length scales, from regional fault networks through main traces of individual faults to the internal structure of fault zones. In this study we examine critically these observations and the mechanical significance of the fractal structures for long-term accommodation of slip on faults.

In the following sections we review observational evidence on the GMM character of faults from a number of different categories of imaging methods and 
data sources. For each category we discuss several classes of observations, distinguished by their imaging resolution and by whether they apply to regional or fault specific studies. The existing data cannot distinguish unequivocally between the three major views on the nature of faults. However, in each observational category the highest resolution results associated with large-displacement mature faults are compatible, in general, with the standard continuum-Euclidean framework. Here the term mature designates an evolutionary stage for which the GMM properties of a fault zone achieve asymptotically stable values. The term mature fault also implies a through-going structure at the largest available scale of a fault network that dominates the tectonic slip accommodation. The observational data, as well as modeling results, indicate that rock deformation has a relatively short initial transient phase involving strain hardening and the creation of granularity and bandlimited fractal structures at several hierarchies. With small increasing deformation under the same applied loads, and high enough strain rate compared to the rate of healing, this process is replaced by strain weakening and localization to tabular zones that become the main carriers of subsequent deformation. At that stage, most of the complex initial structure becomes mechanically passive and the dominant localized fault zones evolve with continuing deformation toward Euclidean geometry and progressive simplicity and regularization. Fault offsets, kinks, and bends, end regions of earthquake ruptures and faults, and transition zones between different tectonic regimes with several active sets of faults, continue to produce local complexity at different scales. However, the overall structural evolution at different hierarchies is toward progressive regularization. Global transient phases of renewed generation of complexity at different scales occur when a mature fault zone rotates away from a favored orientation compatible with the remote loading.

\section{Surface Fault Traces and Structure of Exhumed Fault Zones}

The category of studies discussed in this section is based on direct observations of structural elements ranging from the geometry of surface traces and topography of the wall rocks to the internal geometry of fault zones and particle size distribution of the gouge.

\subsection{Detailed Geological, Geophysical, and Geochemical Measurements on Exhumed Fault Zones}

The data from these works provide multi-disciplinary information on specific fault segments over a range of length scales varying from sub-mm to several $\mathrm{km}$. These studies have broadband widths of both resolution and fault slip and they form the core of the discussion in this section. Chester and Logan $(1986,1987)$, CHESTER et al. (1993), Evans and Chester (1995), Chester and CHESTER (1998) and SCHulz 
and Evans (2000) give extensive field and lab results on the structure of the San Gabriel and Punchbowl faults in southern California. These faults are large abandoned branches of the San Andreas fault system with total slips of several tens of $\mathrm{km}$, and the studied sites have exhumation depths of 3-5 km. Figure 2 shows a mapping example at an intermediate resolution level from the Punchbowl fault zone. At first sight, the figure exhibits all the elements associated with the three different frameworks. The map contains a complex network of faults that divides the medium into blocks of different sizes forming a hierarchy of granularity and shear localizations. However, detailed mapping and a variety of related quantitative analyses have established that most of the $40 \mathrm{~km}$ or so of slip on the Punchbowl fault occurred in a contiguous narrow layer of ultracataclasite that is only $10-20 \mathrm{~cm}$ wide. This extremely narrow Euclidean layer is parallel to the macroscopic slip vector and is referred to as the "core" of the fault zone (CHester and ChESTER, 1998; Schulz and Evans, 2000). Moreover, much of the slip appears to have been accommodated along a single surface within the narrow core layer that is nearly planar in all mapped sections and is referred to as the "principal fracture surface." The ultracataclasite core layer is surrounded by a few $\mathrm{m}$ thick cataclasite layer, which in turn is surrounded by a tabular zone of damaged rock, 100-200 m thick at the Punchbowl

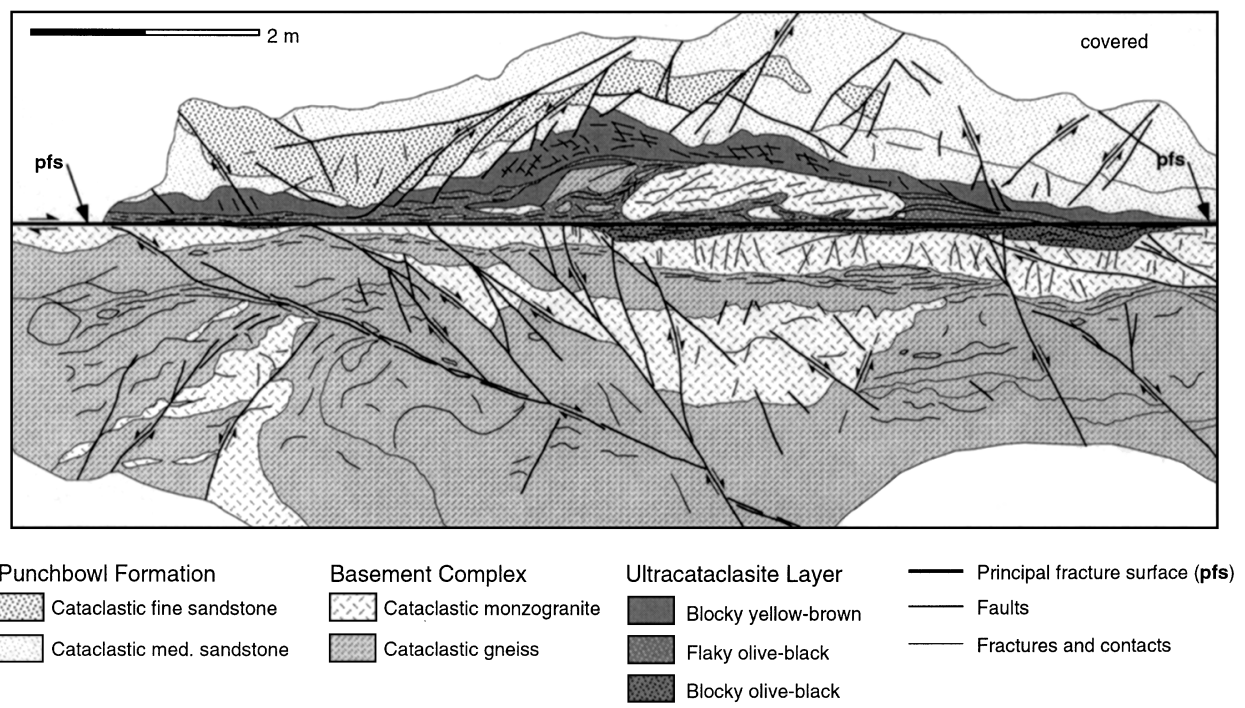

Figure 2

Structure of the Punchbowl fault. The core of the fault consists of an ultracataclasite layer of shear localization with a thickness of $\mathrm{cm}$ to tens of $\mathrm{cm}$ containing a single planar slip surface labeled "principal fracture surface" that accommodated several tens of km of slip. The ultracataclasite layer and principal fracture surface preserve their simple Euclidean character in all exposures in the field area of CHESTER and Chester (1998) and SChulz and Evans (2000). The core structure is surrounded by a tabular zone of cataclastic material that is few $\mathrm{m}$ thick and a broader tabular zone of highly fractured rock with various fault branches that is several hundred $\mathrm{m}$ wide. Modified from CHESTER and Kirschner (2000). 
fault zone, with higher fracture density than the regional background level. The granulation process and shear localizations in the 100-200 m thick damage zone do not appear to have accommodated significant shear strain beyond that associated with their initial formation.

Similar observations characterize the structure of the San Gabriel fault (e.g., Chester et al., 1993; Evans and Chester, 1995), the structure of the Kern Canyon fault at sites with total slip of about $15 \mathrm{~km}$ and exhumation depth over $5 \mathrm{~km}$ (NEAL et al., 2000), and the structure of various faults in the Sierra Nevada at sites with slip up to $150 \mathrm{~m}$ and exhumation depth in the range 4-15 km (EvANs et al., 2000). In all those cases, the fault zone structures have a narrow Euclidean core layer $(2-3 \mathrm{~mm}$ thick in small faults with $10 \mathrm{~cm}$ of slip in the Sierra Nevada; $10-20 \mathrm{~cm}$ thick in the Punchbowl fault with $40 \mathrm{~km}$ of slip) that accommodates most of the deformation, surrounded by a tabular damage zone that is several orders of magnitude wider and is largely passive in slip accommodation. The great similarity in the detailed structures of these faults, having slips and lengths that range over several orders of magnitude, indicates that localization to a dominant narrow core fault zone layer occurs at a very early stage of the shear deformation.

The faults at the Sierra Nevada sites in the study of Evans et al. (2000) underwent an earlier development phase associated with reactivation in shear of a pre-existing set of cooling joints (e.g., Segall and Pollard, 1983; Martel, 1990; Martel et al., 1988). In this earlier phase, reactivated joints formed small strike-slip faults that linked to create a larger through-going shear structure. Further deformation within the network of linked faults then localized to primary slip surfaces at one or both edges of the newly formed fault zone. The earlier phase of fault zone formation by linkage of pre-existing joints may be common to rock domains with a suitably oriented set of joints (e.g., WiLLEMSE et al., 1997). However, the progression from initial activation of a complex network to localization onto a few planar structures is essentially the same as that observed in the other cases described in this section. Aydin and Johnson $(1978,1983)$ documented another style of early development of fault zones in porous sandstone, where deformation bands combine initially to form zones of deformation bands which are then spanned by through-going slip surfaces that become the main carriers of continuing slip. Here too, distributed shear in relatively complex initial structures collapses with slight slip onto simple Euclidean surfaces.

An early transition from an initial complex deformation with a regional network of joints and faults to a narrow localized dominant tabular zone was also pointed out by TCHALENKO (1970), based on several scales of observations, including the rupture zone of the 1968 Dasht-e Bayaz earthquake in Iran and "Riedel" and "shear box" laboratory experiments with clays. TCHALENKO (1970) described the deformation structures in all these and other cases cited in his paper as progressing along three main stages associated with peak strength, post peak strength, and residual strength of the material. The structures in the three stages are formed by creation and different 
arrangements of Riedel, conjugate Riedel, $\mathrm{P}$, and $\mathrm{Y}$ shear zones. In the first stage, around the peak shear resistance, there is a transition from relatively homogeneous bulk shear to deformation dominated by localized Riedel zones, at angles of about $10^{\circ}-15^{\circ}$ to the direction of loading, and a conjugate set of Riedel shears. With increasing displacement of about half the slip-weakening distance in the laboratory experiments, the Riedel shears rotate to shallower angles and become connected by $\mathrm{P}$ and $\mathrm{Y}$ shear zones, while the conjugate Riedel zones are left abandoned. At this stage, estimated by TCHALENKo (1970) to occur in the rupture zone of the Dasht-e Bayaz earthquake at about $250 \mathrm{~cm}$ of slip, the Riedel, $\mathrm{P}$, and $\mathrm{Y}$ shear zones are concentrated in a relatively narrow and contiguous tabular zone. With additional slip for which the strength in the laboratory experiments achieves a stable residual value, estimated by TCHALENKo to be about $300 \mathrm{~cm}$ for the Dasht-e Bayaz earthquake, the structure reached a mature stage and slip becomes concentrated in one or sometime two "principal displacement zones" that are parallel to the direction of loading (Figure 3).

It is interesting to note that the work of TCHALENKO (1970) is often referred to as showing structural complexity at different scales, although he emphasized the similarity at different scales of early structural evolution toward simple narrow zones that accommodate the continuing deformation. A similar evolution from a distributed complex initial deformation toward a simple localized shear is seen clearly in the high resolution acoustic emission experiments of LOCKNER et al. (1992) with different rocks, and in additional types of data discussed below.

\subsection{Analysis of Rupture Surface Topography}

These observations involve specific rupture sites and they have a resolution of sub-mm. In most cases the study sites in this class are joints or fault surfaces with very little slip. Thus the rupture topography data typically describe properties of faults at very initial stages. BROwN (1995) summarized field and lab observations of rough fracture surfaces having self-affine distributions of topography. POWER and TulLis (1991) found that roughness of natural fault surfaces in the direction parallel to that of the slip deviates significantly from self-similarity for length scales larger than about $1 \mathrm{~mm}$, and has a considerably smaller amplitude than the roughness in the direction normal to the slip. The latter is approximately self-similar in the data of Power and TulLis (1991) from about $10^{-2} \mathrm{~mm}$ to about $10 \mathrm{~m}$. A likely explanation for the differences between the amplitude and character of the roughness in the different directions is that cumulative slip tends to smooth the fault surface and make it increasingly more Euclidean-like.

\subsection{Evolution of Fault Trace Complexity with Cumulative Slip}

These works have a resolution on the order of a $\mathrm{km}$ and they fall between those analyzing regional fault networks and those examining specific fault structures. 

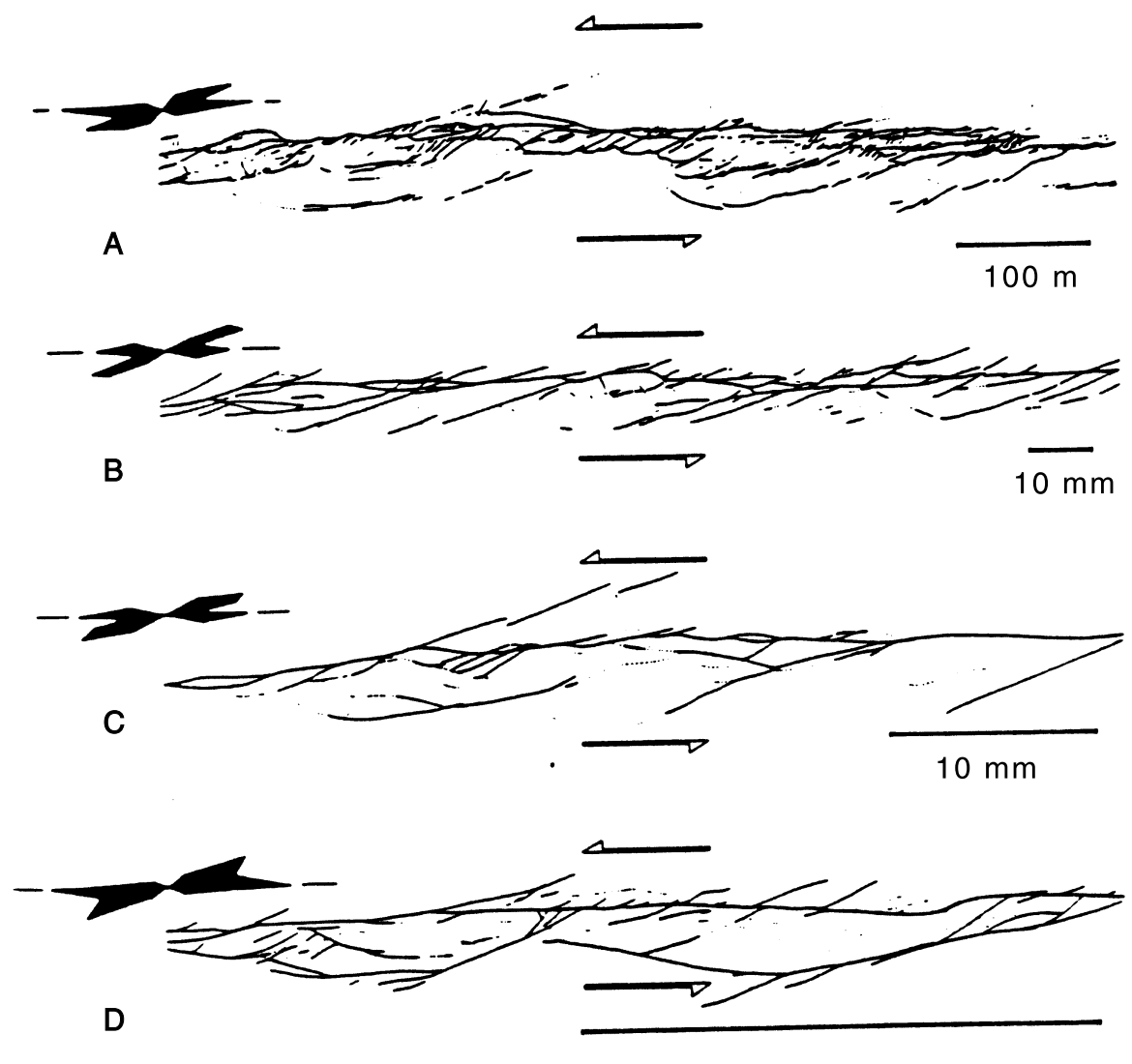

$10 \mathrm{~mm}$

Figure 3

Mature residual structures illustrating localization of deformation at different scales into narrow shear zones that accommodate most of the displacement. (A) Dasht-e Bayaz earthquake in Iran. (B) Riedel experiment with clay. (C) Shear-box experiment with clay. (D) Details of shear-box sample. The rose diagrams show Riedel, P, and principal shear directions at the various scales. From TchaLENKo (1970).

Wesnousky $(1988,1994)$ and StiRling et al. (1996) measured the density of fault steps larger than $1 \mathrm{~km}$ per unit distance along strike for some 30 strike-slip fault zones, and assembled frequency-size statistics of earthquakes on these faults. They found that the step density of the examined fault traces decreases as a function of cumulative slip (Fig. 4a), showing an evolution with continuing deformation from a disordered network of linked fault segments to simpler dominant localized fault zones. These results provide examples of structural regularization at larger scales of fault length and slip than the examples of sections 2.1 and 2.2. WeSNOUSKY (1988) documented an increase in the average segment length of a fault with increasing total slip, consistent with the idea that increasing slip progressively destroys the small-scale structure and produces a more linear fault. AN and SAmmis (1996) simulated fault 
(a)

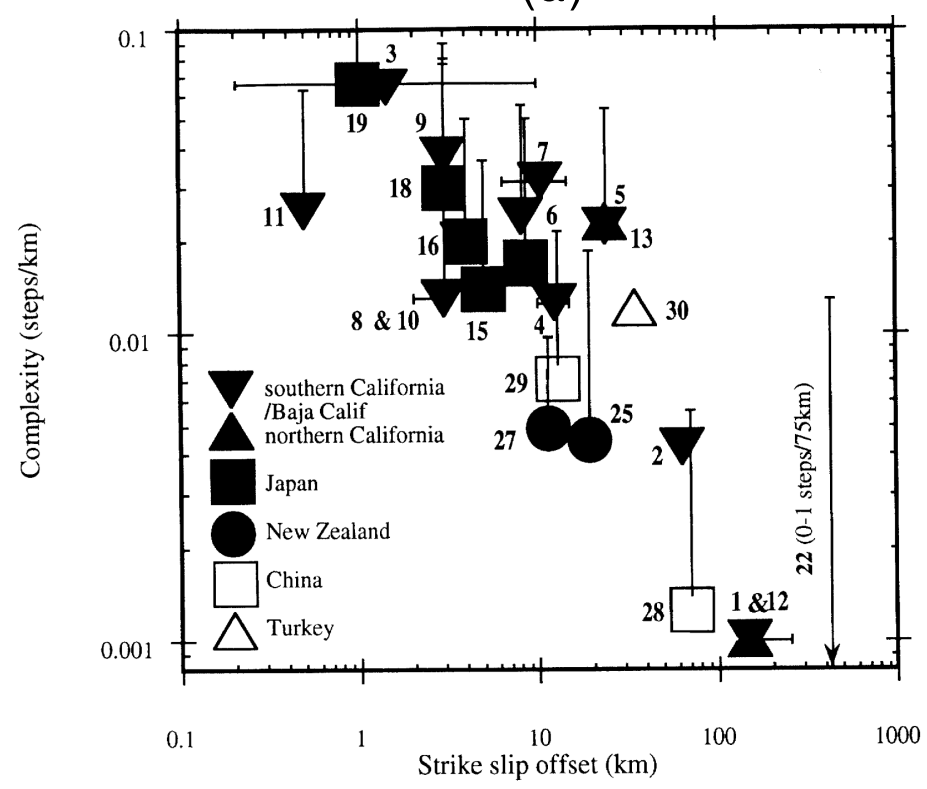

(b)

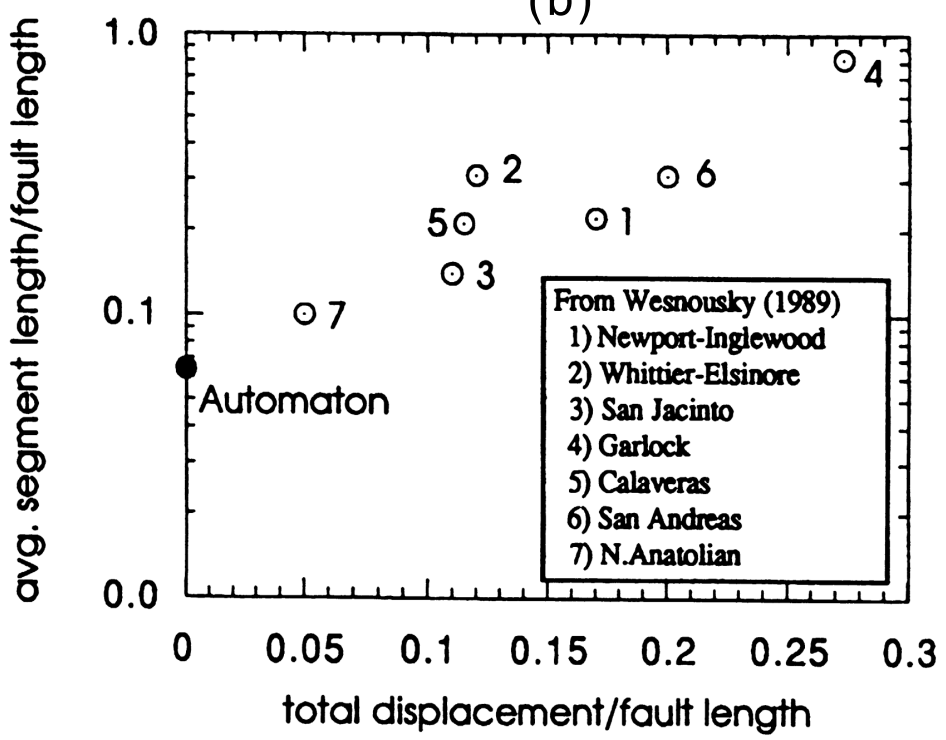

Figure 4

(A) Density of fault steps per unit distance along strike as a function of total strike-slip displacement from STIRLING et al. (1996). (B) Similar results from WESNOUSKY (1989) converted to average segment length per total fault length as a function of total strike-slip displacement. The data are compared with a computer simulation (automaton) by AN and SAMmIS (1996) of crack growth and coalescence at zero slip. 
traces using an automaton model that incorporated physically based rules for the nucleation, growth and interaction of fractures (Fig. 4b). The number of segments per unit fault length for the initial through-going structure was consistent with the scaling found by WeSNOUSKY (1988) in the limit of zero slip.

The compiled frequency-size earthquake statistics of WESNOUSKY (1994) and STIRLING et al. (1996) show a transition from the Gutenberg-Richter power-law distribution on relatively disordered immature faults with small slip, to the characteristic earthquake distribution on relatively regular mature faults with large cumulative slip. These different types of observed statistics as a function of disorder in fault zone properties are compatible with computer simulations and analytical results for models of seismicity patterns along fault systems with different levels of heterogeneity (BEN-ZION and Rice, 1993, 1995; BEN-Zion, 1996; Fisher et al., 1997; DAHMEN et al., 1998). We note that observed power-law earthquake statistics are often assumed to imply an underlying fractal network of faults (e.g., KAGAN, 1992, 1994). However, the above observational and theoretical studies reveal that it is possible to obtain power-law earthquake statistics on individual heterogeneous fault systems occupying narrow or even planar regions of space.

A structural evolution toward increasing localization and simplicity is an expected outcome for deformation in a medium governed by any strain weakening rheology. Figure 5 from LyAKHOVsky et al. (2001) presents examples of structural evolution in computer simulations of coupled evolution of earthquakes and faults in a model consisting of a seismogenic zone governed by damage rheology over a viscoelastic half space. The employed damage rheology is a generalization of Hookean elasticity to a nonlinear continuum mechanics framework accounting for large strain and irreversible deformation (LyAKHOvSKY et al., 1997). The evolving damage in the seismogenic layer simulates the creation and healing of fault systems as a function of the deformation history. The upper crust is coupled viscoelastically to the substrate where steady plate motion drives the deformation. A parameter space study for this model (BEN-ZION et al., 1999; LYAKHOVSKY et al., 2001) indicates that the types of generated fault structures and earthquake statistics are governed by the ratio of the time scale for material healing $\left(\tau_{\mathrm{H}}\right)$ to the time scale for loading $\left(\tau_{\mathrm{L}}\right)$. In general, each brittle failure is associated locally with both strength degradation and stress drop. The value of $\tau_{\mathrm{H}}$ depends on the rheology and it controls the time for strength recovering after the occurrence of a brittle event. The value of $\tau_{\mathrm{L}}$ depends on the boundary conditions and large-scale parameters (which also determine the average time of a large earthquake cycle) and it controls the time for re-accumulation of stress at a failed location. Relatively high ratios of $\tau_{\mathrm{H}} / \tau_{\mathrm{L}}$ (left panels) lead to the development of geometrically regular fault zones and frequency-size statistics of earthquakes compatible with the characteristic earthquake distribution. Relatively low ratios of $\tau_{\mathrm{H}} / \tau_{\mathrm{L}}$ (right panels) lead to the development of highly disordered fault zones and frequency-size event statistics compatible with the Gutenberg-Richter distribution. Interestingly, intermediate cases of $\tau_{\mathrm{H}} / \tau_{\mathrm{L}}$ produce a "mode-switching" 


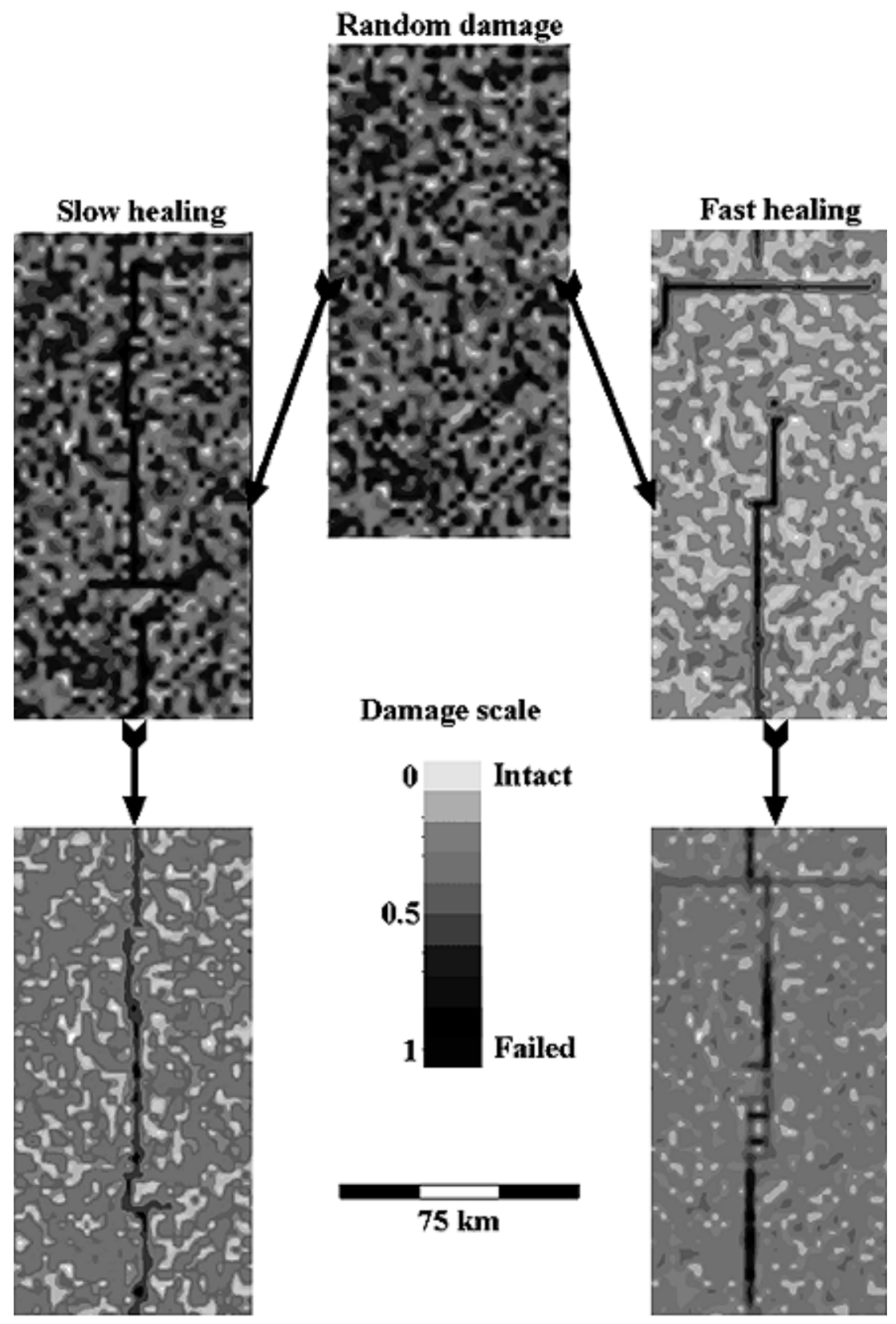

Figure 5

Map views of evolving fault structures in a model consisting of a seismogenic upper crust governed by damage rheology over a viscoelastic substrate. The top central panel shows an initial damage distribution with uncorrelated random heterogeneities. The other panels show evolving damage patterns (fault zones) for cases with relatively slow (left) and fast (right) material healing compared with loading rate. From LYAKHOVSKY et al. (2001). 
behavior in which the fault zone structures and seismicity patterns alternate between time intervals associated with relatively regular structures and characteristic earthquake distribution and intervals associated with relatively disordered structures and the Gutenberg-Richter statistics. The results are compatible with the observations of Wesnousky (1994), Stirling et al. (1996), Marco et al. (1996), and ROCKWELL et al. (2000), as well as with the theoretical results of BEN-ZION and RICE (1993, 1995), BEn-Zion (1996), Fisher et al. (1997), and DAHMEN et al. (1998) for various cases of a heterogeneous planar fault in a continuum solid.

\subsection{Scaling Analysis of Surface Traces of Faults, Internal Fault Zone Structures, and Fault Networks}

These studies may be considered "regional at different hierarchies" and they have various nominal resolutions from sub-mm to several $\mathrm{km}$. However, at each hierarchical level the statistical analyses mix structural units from different deformation phases that may have played significantly different roles in long-term strain accommodation. Thus it is important to try to separate results dominated by structural units reflecting short-lived initial deformation processes from results reflecting properties of long-lived mature surviving structures. Various studies have argued that traces of individual faults have a fractal structure. Aviles et al. (1987) used a ruler method to measure the dimension of the main trace of the San Andreas at several locations. They found dimensions in the range $\mathrm{D}_{0}=1 \pm 0.004$. ОкUво and AKI (1987) used a variant of the standard box counting algorithm to measure the capacity dimension of the main trace plus parallel strands and splays of the San Andreas at several locations, and found a slightly higher dimension $\mathrm{D}_{0}=1.2 \pm 0.2$. These low fractal dimensions close to 1.0 are consistent with shear localization to an essentially Euclidean structure on the active trace of the San Andreas. It is not clear at this point whether the parallel strands and splays analyzed by ОкUво and AKI (1987) are active participants in slip accommodation or are relict structures from an earlier phase of deformation.

Several ideas for the possible mechanical significance of fractal fault traces have been proposed. ОкUво and AKI (1987) suggested that fault segments with an anomalously high fractal dimension may act as barriers to slip propagation by delocalizing shear onto a more complex set of sub-faults. Power et al. (1988) proposed that a fractal fault roughness could provide a mechanism by which fault zones grow wider with increased displacement. While these suggestions are interesting, it is important to note that they are non-unique. For example, BEN-ZION and ANDREws (1998) proposed another explanation, based on the continuum-Euclidean framework, in which fault zone width increases with slip due to wear caused by successive localization of dynamic rupture at the interface between a relatively compliant fault zone layer and a stiffer surrounding host rock. As another example, ANDREWs (1989) 
and HARRIS and DAY (1993) analyzed quantitatively the capacity of fault bends and offsets to act as barriers using planar fault surfaces and continuum mechanics.

MARONE and Kilgore (1993) suggested that the "critical slip distance" $\left(D_{C}\right)$ in rate- and state-dependent friction may reflect a characteristic strain in granular layers, and thus be proportional to the width of fault zone gouge. This can have important implications since the size of the minimum unstable slip patch (and hence the size of the maximum stable nucleation zone) is proportional to $D_{C}$ multiplied by rigidity and divided by strength drop (e.g., DIETERICH, 1986; RICE, 1993; BEN-ZION, 2001). However, the existence of narrow core layers and principal slip surfaces in the large-displacement fault zones of section 2.1, and the observation of very small earthquakes on the San Andreas fault (down to about magnitude $M=-1$ (e.g., NADEAU et al., 1994) with the available recording resolution), indicate that values of $D_{C}$ on mature faults are not very different than those measured in the lab (and hence are not associated with wide granular fault zone layers or other significantly scaledup feature).

Other studies have found evidence for fractal-like features in the internal structure of fault zones. Three structures that are observed to scale are: 1) the topography of the wall rock, 2) the particle distribution of the breccia and gouge, and 3) hierarchical shear localizations. Item 1 was discussed in section 2.2. SAMmIS et al. (1987) and SAMmis and BIEGEL (1989) found a power-law particle size distribution over a range of particle diameters from $10 \mu \mathrm{m}$ to $1 \mathrm{~cm}$ with a fractal dimension in planar cross section of $\mathrm{D}_{0}=1.6 \pm 0.1$. AN and SAMmIS (1994) measured the particle distributions of a suite of natural fault gouges by direct counting. They used sieves for particles in the range $62.5 \mu \mathrm{m}<d<16 \mathrm{~mm}$ and a Coulter-Counter for those in the range $1 \mu \mathrm{m}<d<62.5 \mu \mathrm{m}$. The volumetric fractal dimension of the Lopez Canyon gouge was found to be $2.7 \pm 0.2$, in agreement with $D_{0}=1.6 \pm 0.1$ measured in 2-D section by SAMmis et al. (1987). They also examined particles from gouges of the San Andreas and San Gabriel fault zones in southern California and found a correlation between the peak particle size (by weight) and the fractal dimension. They observed that finer gouges tended to have a higher fractal dimension which they interpreted as being the consequence of the existence of a "grinding limit" at about $1 \mu \mathrm{m}$ (see, e.g., PrAsher, 1987). Chester et al. (1993) analyzed the particle size distributions of cataclasites from the North Branch of the San Gabriel fault. They also found power-law particle distributions with a fractal dimension near $\mathrm{D}_{0}=2.6$. Particles from the Euclidean ultracataclasite layer have a very small upper fractal limit of about $0.1 \mathrm{~mm}$ consistent with strain concentration in this layer.

SAMmis et al. (1987) proposed a mechanism, which they dubbed "constrained comminution," for generating power-law (fractal) particle size distribution in fault gouge based on the geometry of nearest-neighbor inter-grain loading. This term was chosen to distinguish fragmentation under high confining pressures where particles are not able to change neighbors, from the more common crushing and ball milling 
processes where the particles are free to move relative to each other. These latter processes are known to produce Rosin-Ramler and other exponential particle distributions (PRASHER, 1987). However, when the particles are constrained to a given neighborhood during the fragmentation process, their fragility is controlled by the relative sizes of their immediate neighbors. More specifically, a particle is most fragile when it is loaded by neighbors of its size since this configuration produces a bipolar load and maximum tensile stress within the particle. Starting with the largest (weakest) grains in the distribution, constrained comminution selectively eliminates nearest neighbors of same size at all scales. This process leads to a distribution that has no neighbors of the same size at any scale. Sierpinski gaskets and carpets have exactly this property. Further, they are characterized by a fractal dimension of $\mathrm{D}_{0}=1.58$ in 2-D or $\mathrm{D}_{0}=2.58$ in 3-D, similar to that observed in natural gouges. As discussed below, however, the fragmentation process becomes saturated at a relatively small amount of strain and is replaced after an initial transient phase by slip along a dominant localized surface.

BIEGEL et al. (1989) produced power-law distribution of particle sizes in the laboratory, which they characterized over the range $0.02-0.6 \mathrm{~mm}$, by deforming a $3 \mathrm{~mm}$ thick layer of $750 \mu \mathrm{m}$ rock fragments between the sliding rock surfaces of a double-shear friction apparatus. After a shear strain of only about 1, the distribution had evolved into one that looked very similar to the cross sections from natural fault zones (Fig. 6 top). Measurements of the fragment size distribution yielded $\mathrm{D}_{0}=1.6$ in 2-D section, consistent with measurements in natural gouges. MARONE and SCHOLz (1989) also produced fractal gouge in the laboratory using a triaxial saw-cut testing configuration. STEACY and SAMmIS (1991) used a computer automaton to show that the systematic elimination of same-sized nearest neighbors does indeed lead to a random fractal distribution with a dimension $\mathrm{D}_{0}=2.6$ in 3-D. BIEGEL et al. (1989) demonstrated that the initial evolution to a fractal particle size distribution is closely related to the transition from a velocity strengthening to a velocity weakening friction commonly observed in granular layers (Fig. 6 bottom). Initially, shear strain is accommodated mostly by grain fracturing, which is inherently a strengthening process. However, with the emergence of a fractal distribution, an increasing proportion of shear is accommodated by slip between the grains that is associated with time-dependent contact strength leading to velocity weakening. The elimination of same-sized neighbors in the initial transient deformation phase minimizes the fragility of grains, thereby suppressing fracture. The same process also minimizes dilatancy, thereby enhancing slip. SAMmis and STEACY (1994) used the friction data from BIEGEL et al. (1989) in a "grain-bridge" model to quantify this change in friction behavior.

Deformation within fault zones is usually localized on a set of Riedel shears (e.g., Fig. 3) as noted earlier on by TCHALENKo (1970). Occasionally one finds a nested hierarchy of Riedel shears within Riedel shears. A well documented example of such a hierarchy was discussed by ARBOLEYA and ENGELDER (1995) who observed three 

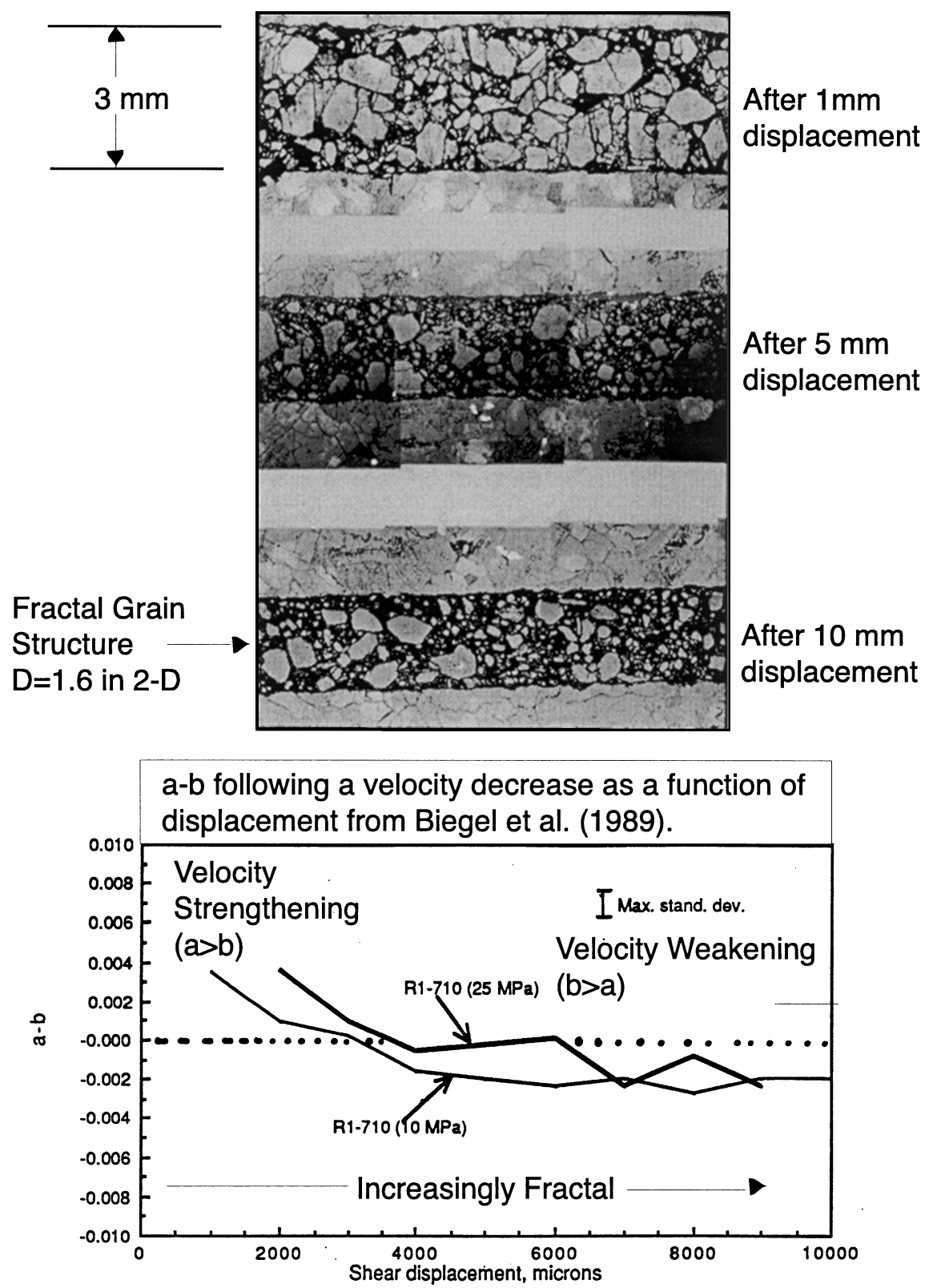

Figure 6

Transition from grain crushing (hardening) to shear localization (weakening) in a granular layer deformed in simple shear. The upper panel shows cross sections of a portion of the layer after 1, 5 and $10 \mathrm{~mm}$ of shear displacement. Note the isolation of particles of all sizes leading to the formation of a fractal grain structure as proposed by SAMmis et al. (1987). The lower panel shows the evolution with slip of the combination of parameters $a-b$ of the rate and state-dependent friction law. The friction has a transition from velocity strengthening $(a>b)$ and stable slip to velocity weakening $(b>a)$ and potentially unstable slip. The figures are from BIEGEL et al. (1989) who argue that the change in mechanical behavior is due to the establishment of a fractal grain distribution. 

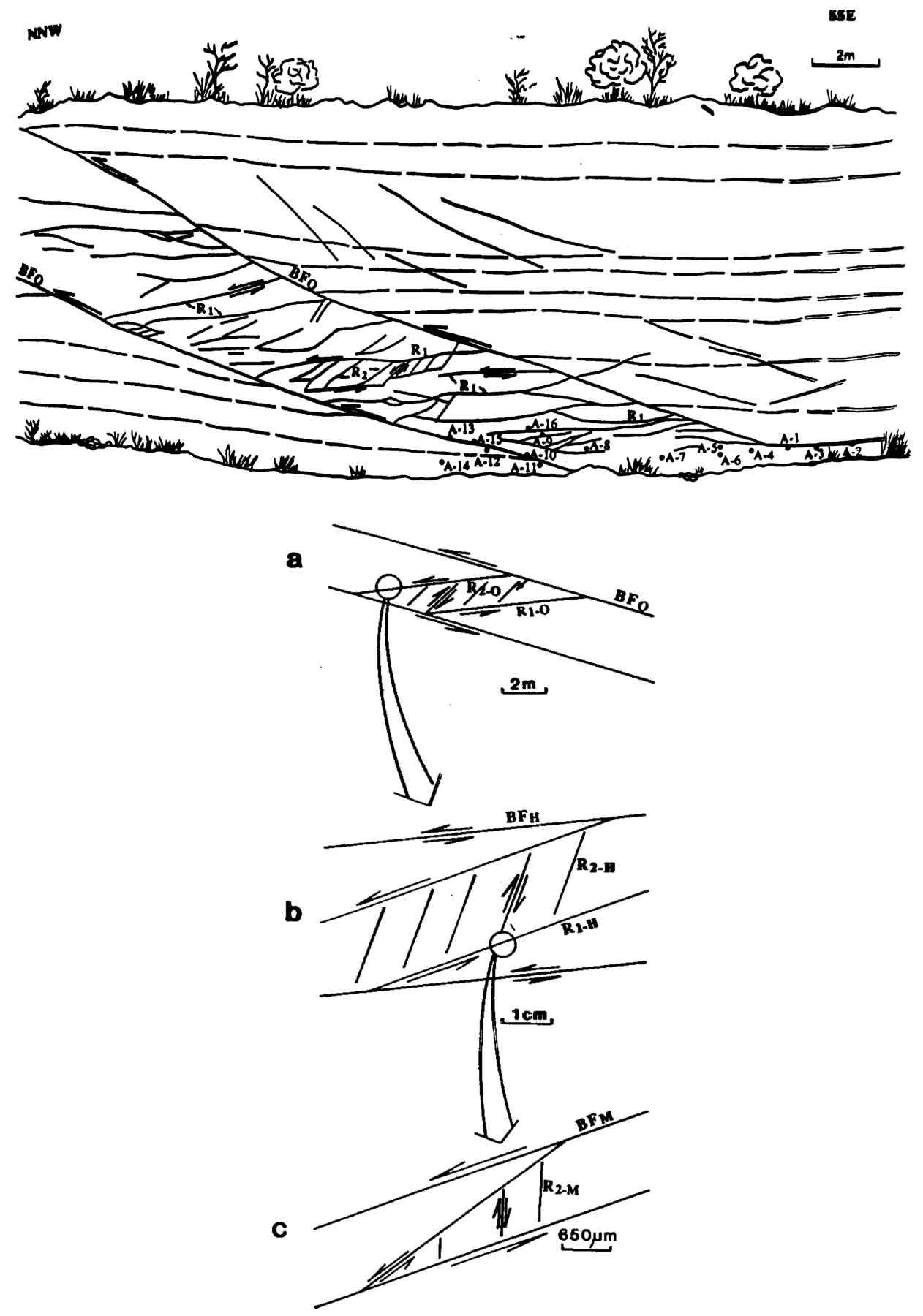

Figure. 7

A nested hierarchy of shear localizations from ARBOLEYA and EnGELDER (1995). The mapped section is shown on top and the interpretation as a nested hierarchy of Riedel shears is given at the bottom. 
nested sets of Riedel shears in the Cerro Brass fault zone in the Appalachian valley and ridge province in central Pennsylvania (Fig. 7). The evolution of a hierarchical set of nested Riedel shears may be closely related to the evolving grain structure. Once a band-limited power-law distribution of grain sizes is established between upper and lower scales related to physical properties of the system, diminished dilatancy will cause strain to localize into Riedel shears. The whole process then repeats at the smaller scale. A band-limited fractal distribution emerges within the Riedel shear that leads to localization to a set of Riedels within the Riedel, and so on. As mentioned earlier, however, these structures typically form early on and they do not accommodate large slip. Ultimately, the grinding limit is reached and slip remains localized on a through-going $\mathrm{Y}$ shear parallel to the macroscopic slip vector as discussed in section 2.1. The planar zone of shear localization that was found in the Punchbowl fault zone by CHESTER and CHESTER (1998) is probably an example of such a structure.

The idea that most fault gouge and breccia are formed at low strains is supported by SibSON (1986) who identified three categories of natural gouge: a) attrition breccia due to wear, b) distributed crush breccia formed by the destruction of local asperities, and c) implosion breccia formed by sudden decreases in fault zone pressure (usually at dilatational jogs and bends). Of the three, only the first is associated with significant fault slip. It is characterized by rolled clasts and is relatively rare. The other two are characterized by pervasive microfractures and a jigsaw texture and are far more common.

At the plate boundary scale, deformation is accommodated on a network of faults often having a width on the order of tens of kilometers. Various studies claimed that fault networks also have fractal structure. HiRATA (1989) found that the mapped surface traces of fault systems in Japan are self-similar over scales from 2 to $20 \mathrm{~km}$. He used a box-counting technique to measure a fractal dimension of 1.5 to 1.6 in the more heavily faulted central part of the Japan Arc. SAmmis et al. (1992) also used a box-counting algorithm to demonstrate that the surface expression of the fault network in the Geysers geothermal field in northern California has a fractal dimension of $\mathrm{D}_{0}=1.9$ over the range from 0.8 to $10 \mathrm{~km}$. LEARY (1991) discussed results based on analysis of various quantities in geophysical boreholes (e.g., sonic velocity, mass density, porosity) and seismic coda waves. From long-range correlations in these data he concluded that the fracture density in the crust follows a fractal distribution.

OUILLON et al. (1996) used a wavelet analysis to measure the structure of fault networks on the sedimentary cover of Saudi Arabia at scales from $1 \mathrm{~cm}$ to $100 \mathrm{~km}$. They found a multifractal pattern in which the fractal dimension and anisotropic fabric were different for distinct ranges of scale-length separated by characteristic dimensions that correspond to known rheological and lithological units in the Arabian crust. Scholz (1991) noted a transition in geometrical properties of fault segments in the San Andreas system and the rupture zone of the Dasht-e Bayaz 
earthquake in Iran at a size scale corresponding to the width of the seismogenic zone. The fault networks at these locations appear self-similar at length scales smaller than the seismogenic depth. However, at larger scales the network is replaced by a single through-going structure. As with other items in this section it is not clear whether all the fractures and faults in the regional networks have long-term mechanical significance, or whether most of the displacement is carried by a few dominant structures. The last two references and fractal analyses of regional seismicity discussed below suggest the latter.

Why such structures exhibit fractal characteristics is still an open question. KING (1983) pointed out that 3-D brittle deformation is accommodated in general by several faults, and that fault bends, junctions, and other geometrical irregularities lead to generation of additional smaller scale faults. He suggested that the attractor of this process is a fractal network of faults and showed that such a network can accommodate complex deformation patterns. The process envisioned by KING (1983) is based essentially on purely geometrical considerations in a uniform solid and it involves a cascade of deformation structures from large faults to small ones. However, evolution of material properties that accompanies faulting and slip, not considered by KING (1983), can lead to structural evolution in the opposite direction. The multi-disciplinary observations reviewed in this paper suggest that "large-to-small" cascades of structures characterize transient phases of deformation at different scales that are superposed on "small-to-large" longer-term evolution involving smoothing of geometrical irregularities, coalescence of small segments, and the weakening-localization positive feedback mechanism discussed earlier.

ROBERTSON et al. (1995) suggested that faulting is an example of a percolation process. In this explanation, the fractal structure observed at the surface corresponds to the percolation threshold. However, they suggested that once the percolation threshold is achieved, deformation localizes to the percolation backbone since this is the through-going structure that can accommodate the plate boundary motion. We return to this issue in section 5. Another possibility is that brittle deformation at plate boundaries granulates the entire crust. As discussed for internal fault zone structures, fragmentation in shear with strong constraints on dilatation, as expected to exist at seismogenic depths with normal pore pressure conditions, produces a band-limited fractal distribution of block sizes having a fractal capacity dimension of $\mathrm{D}_{0}=1.6$ in planar section. In this interpretation, faults are the boundaries of the blocks. Major faults such as the San Andreas represent major shear localizations within the block structure. Gallagher (1981) proposed such a block model for crustal deformation in China based on regional satellite images. FREUND (1974) and NUR et al. (1989) made similar suggestions for the crust in Israel and California. A blocky crustal model is also supported by concentration of deformation signals along block bounding faults (e.g., BEN-ZION et al., 1990), long-range correlation of precursory seismic 
activity (e.g., KeILIS-BoroK and Kossobokov, 1990), and rotated coherent terrains (e.g., LUYENDYK, 1991). However, the strong anisotropy of fields implied by a truly blocky (granular) structure is not observed in general. This is indicated, for example, by successful routine modeling of regional seismic (e.g., Wald, 1992; Zhu and Helmberger, 1996) and geodetic (e.g., Segall and DAVIS, 1997; BURGMANN et al., 2000) fields generated by earthquakes in terms of dislocation surfaces in elastic solid. As discussed earlier, the complex regional fault patterns often visible at the surface are probably relic structures of earlier deformation phases that do not contribute significantly to the long-term slip accommodation.

Most studies discussed in this section are based on direct observations of fault zone properties although they are limited to structures that are presently at the surface. One possible objection to these observations is that they may not represent structures that are currently active at seismogenic depths. In general, fault structures at seismogenic depth are expected to be simpler than shallow structures because increasing pressure and temperature tend to suppress brittle branching and other sources of structural complexity. In the next section we summarize observations of in situ fault structures at seismogenic depths, based on various indirect geophysical imaging methods.

\section{Inversions of Geophysical Data}

This category of works involves inferences relative to the geometry and material properties of faults using standard geophysical techniques including gravity, electromagnetic surveys, and seismology.

\subsection{Gravity Anomalies}

These are regional studies, although they can center on specific faults, with a resolution on the order of a few $\mathrm{km}$. STIERMAN (1984) found a Bouguer gravity low along the San Jacinto fault in southern California and concluded from modeling the data that the fault at seismogenic depth is surrounded by a several $\mathrm{km}$ wide tabular zone of damaged rock with reduced mass density. WANG et al. (1986) obtained a similar conclusion from a gravity study across the Bear Valley section of the central San Andreas fault.

\subsection{Electromagnetic Signals}

These are also regional studies that may center on specific faults. In general, the resolution of these and seismic studies depends on the spatial distribution of sources and receivers, ranges of frequencies generated by the sources and detectable by the (surface or sometimes shallow borehole) receivers, the portion of the source- 
receiver path spent in the fault zone itself, and whether travel time or whole waveform observations are used. EBERHART-PHILLIPs et al. (1995) reviewed various electromagnetic and seismic techniques and concluded based on synthetic data tests that typical electromagnetic studies have a resolution on the order of a few $\mathrm{km}$. A dense instrument spacing may increase the resolution of electromagnetic surveys to $500 \mathrm{~m}$ or so (UNSWORTH et al., 1999). The electromagnetic methods provide an image of structural resistivity (or conductivity) that may be interpreted in terms of various manifestations of damaged fault zone rock (high fluid pressure, clay minerals, and/or deposited conductive minerals). Eberhart-Phillips and Michael (1993), MaCKIE et al. (1997), and Unsworth et al. (1999) found that various sections of the San Andreas fault are associated with prominent tabular resistivity structures.

\subsection{Seismic Reflection/Refraction and Travel-time Tomography}

These methods are lumped together here because they all use seismic travel time (and sometime also amplitude) information, as opposed to waveform modeling. Studies in this class have typically a resolution of up to about $500 \mathrm{~m}$, and like the previous two classes they are regional surveys that may center on specific faults. EBerhart-Phillips et al. (1995) give an excellent review of various seismic (and electromagnetic) methods, and their ability to image fault zone properties. Additional reviews of reflection/refraction seismology and travel-time tomography are given by MoOney (1989) and Thurber (this volume). Reflection/refraction surveys are not well suited for imaging narrow vertical structures. They have been used widely to image sub-horizontal structures and results typically show, within the imaging resolution, Euclidean fault structures (e.g., MoONEY and BROCHER, 1987; Fuis and Mooney, 1990). Travel-time tomography has a better ability to image vertical structures; in the first application of body-wave tomography to fault imaging, AKI and LEE (1976) found a tabular low velocity fault zone layer along the San Andreas fault south of Hollister.

One general shortcoming of regular seismic tomography is that $P$ and $S$ body waves tend to avoid low velocity media. This, together with the fact that each travel time is a function of the entire source-receiver path, limits considerably the ability of body-waves tomography to image narrow low-velocity structures. An improvement in the imaging resolution may be obtained by adding travel-time information of phases that spend much of their travel path along the fault zone structure. BEN-Zion et al. (1992) developed a joint travel-time tomography of body waves and fault zone head waves that propagate along material interfaces in the fault zone structure. Application of the method to a small data set from the Parkfield segment of the San Andreas fault led to separate depth profiles of seismic velocities for the different sides of the fault, consistent with the existence of a sharp Euclidean contrast across the fault. Regular tomographic inversions of large data sets of body-wave arrivals at Parkfield show a several $\mathrm{km}$ wide 
transition zone of $P$ and $S$ wave velocity across the fault with a possible internal low velocity layer (e.g., LeEs and Malin, 1990; Michelini and McEvilly, 1991; Eberhart-Phillips and Michael, 1993). Similar tomographic images are found along other sections of the San Andreas and other faults (e.g., Feng and McEvilly, 1983; Michael and Eberhart-Phillips, 1991; Eberhart-Phillips and MiChaEL, 1998).

\subsection{Seismic Fault Zone Guided (Head and Trapped) Waves}

The highest imaging resolution of fault zone structure at depth with surface or shallow observations is probably provided by waveform modeling of seismic fault zone head and trapped waves. These studies can have a resolution on the order of meters to tens of meters and they involve specific fault segments. Fault zone head and trapped waves can exist only in structures that are sufficiently Euclidean and uniform to act as a waveguide. As mentioned above, fault zone head waves propagate along material interfaces in the structure. Fault zone trapped waves are generated by constructive interference of critically reflected phases within low-velocity fault zone layers.

Fault zone head waves have been observed along the subduction zone of the Philippine Sea plate underneath Japan (FUKAO et al., 1983), the Parkfield segment of the San Andreas fault (BEN-Zion and MALIN, 1991; BEN-Zion et al., 1992) and small fault segments in the aftershock zone of the 1992 Joshua-Tree California earthquake (Hough et al., 1994). Fault zone trapped waves were observed along the Philippine Sea plate underneath Japan (FuKAO et al., 1983), the Middle America Trench near Mexico (SHAPIRO et al., 1998), a small normal fault in Oroville, California (LEARY et al., 1987), several segments of the San Andreas (Li et al., 1990, 1997; MicHAEL and BEN-ZION, 2002) and San Jacinto (Li et al., 1998) faults, and the rupture zones of the 1992 Landers, California (Li et al., 1994; Peng et al., 2000), 1995 Kobe Japan (Li et al., 1998; Nishigami et al., 2000; Kuwahara and ITO, 2000), and 1999 Izmit Turkey (BEN-Zion et al., 2000) earthquakes.

At present there are still considerable uncertainties in the interpretation of these observations due to the nonuniqueness of modeling and the limited scope of the analysis to date (BEN-ZION, 1998; MiChaEL and BEN-ZION, 2002). Collectively, however, the observations of fault zone head and trapped waves along a number of fault and rupture segments where detailed data are available indicate that fault structures at depth have coherent Euclidean interfaces and/or low-velocity layers that are tens to hundreds of meters wide. The inferred low-velocity fault zone layers are in good correspondence with the tabular damage zone around the narrow core slip regions discussed in section 2.1 .

None of the geophysical imaging techniques can resolve dominant slip zones and fracture surfaces, and the tabular damaged zones imaged by the methods of sections 3.1-3.3 are probably blurred versions of the true structures. These tabular 
damaged zones may have important implications for fluid flow in the crust and a variety of related issues, however they are probably not the key mechanical structures accommodating the major long-term cumulative slip. To find evidence for properties of the key mechanical structure at seismogenic depth we discuss in the next section relations between various model predictions and earthquake observations.

\section{Model Predictions}

Since theoretical models of earthquakes and seismicity are predicated on an assumed GMM formulation, their success or failure at predicting observations bears directly on the problem of identifying the most suitable GMM framework. We now review several classes of theoretical models from this perspective. The spatial extent and resolution of the different classes depend on the observations used to validate model prediction and are not specified explicitly as done in sections 2,3 , and 5.

\subsection{Seismic Radiation}

A major triumph of modern seismology is the development in the last few decades of a quantitative ability to model successfully, with Euclidean surfaces and continuum-elastodynamics, seismic waves at all observed frequencies (e.g., AKI and RICHARDS, 1980). Some rupture and wave propagation models assume a selfsimilar collection of slip patches; however, those are modeled as occurring along planar surfaces in a continuum solid so mechanically the corresponding models still belong to the continuum-Euclidean framework. For example, ANDREws $(1980,1981)$ pointed out that observed $\omega^{-2}$ spectral decay of ground acceleration and $b$-value of frequency-size (FS) earthquake statistics of about 1 can be generated by self-similar distributions of slip and stress on a planar fault. ZENG et al. (1994) and HERRERO and BERNARD (1994) simulated strong ground motion compatible with observed accelerograms with frequencies up to several tens of $\mathrm{Hz}$ by summing contributions from a self-similar distribution of slip patches, each radiating a dislocation pulse with a random phase, on a planar fault. It is of course possible that higher frequency waves that attenuate within the source region and do not reach the receivers are not compatible with slip on planar surfaces. To constrain the mechanical structure at the earthquake source region we must consider source phenomena that are observable at the earth surface. This leads us to predictions of mechanical models associated with spatio-temporal seismicity patterns.

\subsection{Earthquake Triggering and Migration}

Various studies have modeled observed changes of seismicity rates and space-time patterns of earthquake failure sequences in terms of stress transfer between frictional 
planar fault surfaces in a continuum solid (e.g., HARRIS, 1988; KING and CocCO, 2001, and references therein). As examples, SiMPSON and REASENBERG (1994) used such a framework to model changes of seismicity rates in the San Francisco Bay area following the 1989 Loma Prieta earthquake. STEIN et al. (1994) demonstrated that the main spatio-temporal characteristics of moderate to large earthquakes and their aftershock sequences in southern California over recent decades may be explained by interactions governed by elastic stress transfers between frictional planar faults. HARRIS and SimpSON (1996) showed that space-time patterns of earthquakes in southern California in the 100 years following the great 1857 earthquake are compatible with elastic stress transfer generated by a continuum-Euclidean model of that event. Perhaps most impressively, STEIN et al. (1997) calculated with such a model elastic stress transfers associated with the remarkable 1942-1992 progression of ruptures along the North Anatolian fault. Significantly, the two largest subsequent earthquakes on the fault, the August and November 1999 M > 7 events, occurred along segments that fall within a region predicted to have high triggering stress by these calculations. NALBANT et al. (1998) modeled evolving seismicity in the more complex western end-region of the North Anatolian fault with elastic stress transfers between numerous frictional planar faults.

\subsection{Rupture along a Material Discontinuity Interface}

Weertman (1980), Adams (1995), Andrews and Ben-Zion (1997) and others studied properties of dynamic rupture along a frictional planar interface between two different elastic solids. The studies indicate that a material discontinuity interface is a mechanically favored surface for rupture propagation. The sharp material contrast across the rupture plane leads to several additional model predictions. These include (1) a mode of rupture in the form of a narrow self-healing pulse associated with low generation of frictional heat, (2) asymmetric motion on the different sides of the fault, and (3) preferred direction of rupture propagation as that of the slip in the more compliant material (Fig. 8). Item (1) is compatible with inferred earthquake properties (e.g., HEATON, 1990; BRUnE et al., 1993), however it may also be generated by a number of other mechanisms (see BEN-ZION, 2001, for a recent review).

Figure 8

(Top) Particle velocities at a given time for rupture along a material interface (thin horizontal line) separating elastic solids with $20 \%$ contrast of shear-wave velocities and mass densities. The slipping region is marked by the short thick segment on the fault and is propagating to the right. The existence of a material contrast across the fault produces an asymmetric motion in the different media that is especially prominent near the fault. (Bottom) A closer view around the fault (note changes in scales). Particle velocities in the more compliant material $(y>0)$ are larger than in the stiffer medium $(y<0)$. This leads to dynamic reduction of strength at the rupture front that enables slip to occur as a narrow wrinkle-like pulse. Spontaneous propagation occurs only in one direction, that of the slip in the more compliant medium. From BEN-ZION (2001). 

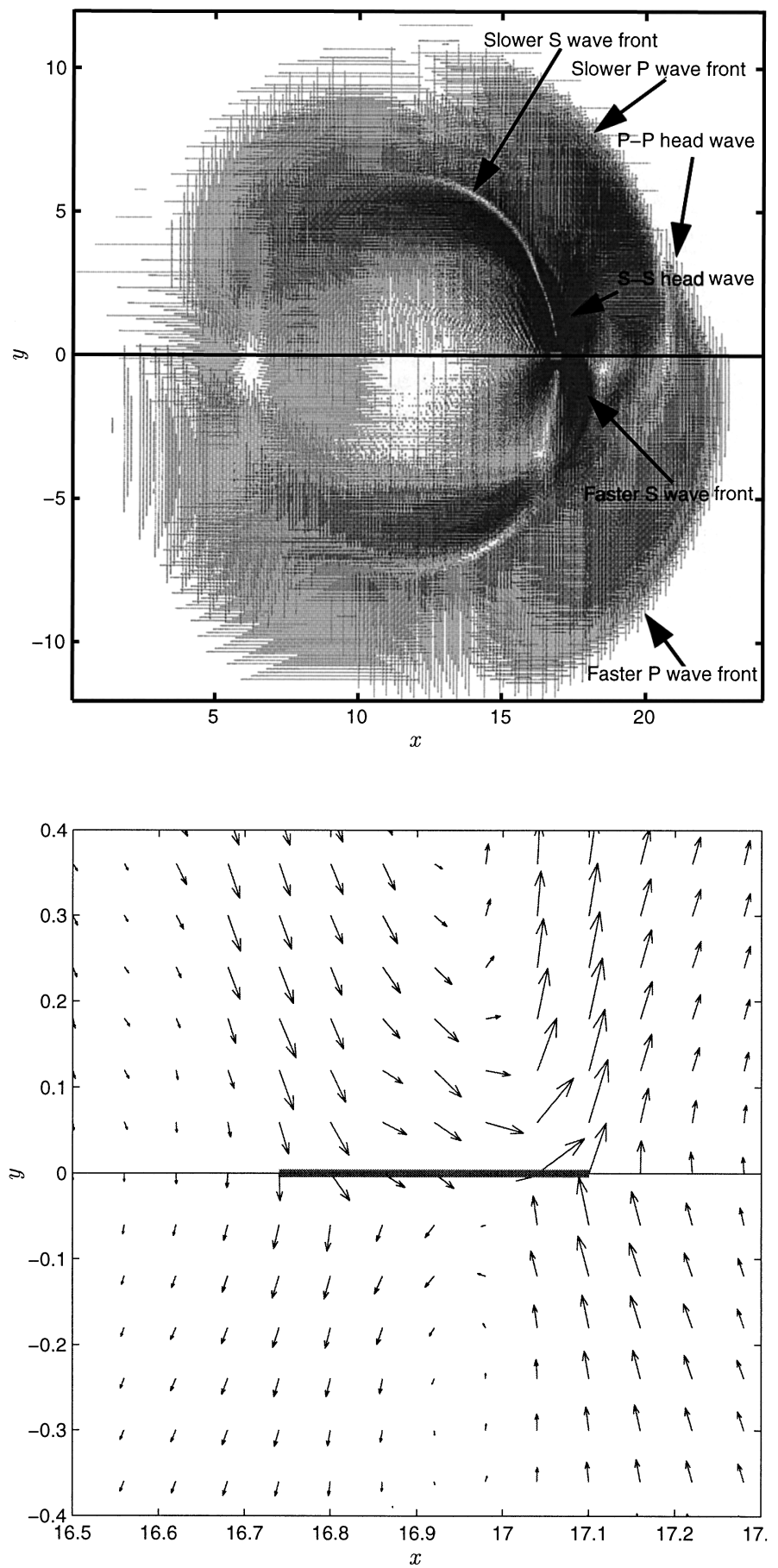
However, item (3) and to a lesser extent also item (2) are specific to rupture along a material interface.

RUBIN and GILlaRd (2000) examined space-time properties of high-resolution locations of small earthquakes, obtained by a waveform cross-correlation technique, along the San Andreas fault north of San Juan Bautista, California. They found that the number of immediate aftershocks near the edges of prior ruptures to the northwest is more than double the number to the southeast. The strong asymmetry of aftershocks in the different directions was interpreted by RUBIN and GILLARD (2000) to be a manifestation of item (3), associated with rupture along a material contrast across the fault in that region. MCGUIRE et al. (2000) analyzed source properties of about 30 global large earthquakes and found that rupture propagation of most events was predominantly unidirectional. This observation is compatible with a tendency of rupture to localize along a material interface between a relatively compliant fault zone layer and a stiffer surrounding rock, in agreement with the prediction of the above continuum-Euclidean models. Direct field studies also indicate that rupture commonly localizes near the boundary between a damaged fault zone layer and the host rock (MARTEl et al., 1988; BRUHn et al., 1994; SibSON, 1999).

\subsection{Statistics and Patterns of Earthquakes}

KAGAN and KNOPOFF (1981) and KAGAN (1982) argued that earthquakes and faults are rough fractal processes and objects in space-time. Their argument is based on analysis of hypocenter locations discussed in the next section, and extrapolations of aftershock decay rates and strong ground motion to zero space and time distances from the generating sources, assuming strict self-similarity on trajectories having singularities at the sources. Since in situ measurements directly at the earthquake source are non-existent, such extrapolations are permissible in principle; however they are certainly not required by the available data. As noted in section 4.1, seismic radiation can be explained at all observed frequencies by heterogeneous distribution of dislocation sources on a planar fault. In continuum-Euclidean models, aftershock rates are truncated at short time due to initial build-up processes before instabilities associated with nonlinear rheology (e.g., DIETERICH, 1994; LOCKNER, 1998). This is reflected empirically by the positive constant $c$ in the modified Omori law for aftershock rates, $\Delta n / \Delta t \sim(t+c)^{-p}$, where $n$ is number of events, $t$ is time, and the exponent $p$ is close to 1 . Observed values of $c$ are derived based on incomplete recordings close in space-time to the mainshock and other uncertainties, so it is possible that $c$ is essentially zero. However, UTSU et al. (1995) examined this possibility and concluded from high-resolution and corrected observations that actual $c$ values are positive. DIETERICH (1994) showed that Omori's law can emerge directly from delayed nucleation associated with rate- and state-dependent friction observed in the laboratory, and does not require a fractal structure (see also LOCKNER, 1998). 
KAGAN $(1992,1994)$ summarized various power-law distributions of earthquakes and concluded that the scale-invariant statistics and great irregularity of earthquake occurrence imply underlying fractal structures. Again, this is possible but not required since power-law statistics and complex space-time patterns can be generated by heterogeneous continuum-Euclidean models with many degrees of freedom, as well as by other models. For example, Ben-Zion (1996), Fisher et al. (1997), and DAHMEN et al. (1998) showed numerically and analytically that heterogeneous planar idealizations of segmented faults in an elastic solid can produce frequency-size, temporal, and spatial statistics of earthquakes that are compatible with observations covering broad ranges of space and time scales. In fact, for some parameter values these models generate fractal slip patterns (FISHER et al., 1997). Thus the complex earthquake phenomenology does not necessarily imply by itself any specific framework.

Another approach for imaging the geometry of faults is based on hypocenter distributions. Hypocenters provide an image of nucleation zones of brittle instabilities rather than entire fault zones, and they tend to cluster around geometrical and mechanical heterogeneities. Thus geometrical properties of hypocenters are probably more complex than those of earthquake ruptures and faults. Nevertheless, high resolution hypocenter locations appear to collapse on simple structures, as discussed in the next section.

\section{Hypocenter Distributions}

The spatial distribution of hypocenters helps to illuminate the geometry of the faults on which they occur. For individual faults, accurately located hypocenters should give a measure of the width of the slip localization zone and reveal evidence of spatial heterogeneity. For fault networks, hypocenters preferentially illuminate the most active elements and help to determine how the system accommodates regional strain.

\subsection{Spatial Correlations among Routine Locations in Regional and Global Catalogs}

These are regional studies and they have a resolution on the order of a few $\mathrm{km}$. KAGAN and KNOPOFF (1980) and KagAN (1981a, 1981b) estimated the spatial structure associated with seismicity patterns by calculating 2-, 3-, and 4-point correlation functions among hypocenters in the central California earthquake catalog. KagAN (1981b) concluded in a summary of this set of works that the hypocenter locations reside on a self-similar volumetric branching structure. KAGAN (1991) measured the pair correlation of hypocenters in a global earthquake catalog to estimate the spatial fractal dimension of global seismicity. He obtained a correlation dimension of $\mathrm{D}_{2}=2.1-2.2$ for shallow seismicity, 1.8-1.9 for intermediate depth 
events, and 1.5-1.6 for deep focus events. It is important to verify the results of these works by independent new studies using higher resolution data. We also note that a volumetric branching structure of hypocenters does not necessarily imply that the ruptures themselves do not reside, to a good approximation, on a collection of Euclidean surfaces.

\subsection{Geometry and Analysis of Improved Locations}

These are also regional studies but they have a resolution varying from a few hundred meters to about a km. ROBERTSON et al. (1995) used a 3-D box-counting algorithm to find the capacity dimension $\mathrm{D}_{0}$ of seismicity in relocated aftershock sequences in southern California. They found the surprising result that the fractal dimension is only 1.8 in 3-D for those catalogs that had the smallest location errors, and a slightly larger value for catalogs with lower resolution. The low dimension was interpreted as evidence for localization of seismicity on the backbone of a critical percolation structure in 3-D, which is also 1.8. This interpretation is consistent with our hypothesis that most of the active deformation is localized on a small subset of the regional network, much of which is remnant from earlier phases of deformation. The results indicate that the entire fault network is not populated with earthquakes. Only the subset of faults that form a connected structure and allow finite shear (the percolation backbone) is active. More recently, RichARDS-Dinger and SHEARER (2000) relocated the 1975-1998 seismicity in southern California using a distribution of station corrections that varies as a function of the earthquake positions. They have not attempted a fractal analysis, however visual inspection indicates that the relocated hypocenters tend to collapse, compared to the original locations, toward tabular Euclidean structures.

\subsection{High-resolution Relocations of Local Network Catalogs}

The highest-resolution locations are based on waveform cross correlation, sometimes done jointly with other methods (e.g., POUPINET et al., 1984; ITO, 1985; Got et al., 1994; NAdeAu et al., 1994; Dodge et al., 1995; Shearer, 1997; RubiN et al., 1999; Waldhauser et al., 1999; Rubin and Gillard, 2000). These results apply to specific fault segments or aftershock sequences and they have a resolution on the order of meters to tens of meters. In all these studies the hypocenters collapse toward regular Euclidean structures consisting of one or more planar subparallel segments. In no case do the high-resolution results show a fractal branching structure emerging from the original cloud of the standard locations.

The hypocenter locations on fault segments which have a large component of aseismic creep (NADEAu and McEvilly, 1997; NAdEAu and Johnson, 1998; Rubin et al., 1999; RUBIN and GILLARD, 2000) show interesting spatio-temporal patterns such as repeating events, linear streaks, clustering of immediate aftershocks along edges of 
Mode II crack shapes, and preferred direction of rupture propagation. These patterns have been interpreted in terms of strength heterogeneity on a fault plane (SAMmis et al., 1999; SAmmis and Rice, 2001; BeELer et al., 2001), standard fracture mechanics (RUBIN and Gillard, 2000), and rupture along a sharp material contrast across the fault (see section 4.3).

\section{Discussion}

We now return to our original questions: what is the best framework for modeling crustal deformation and how does the answer depend on scale? The multidisciplinary results reviewed in the paper suggest consistently that fault structures tend to evolve with cumulative slip (Fig. 9) toward geometrical simplicity and the continuum-Euclidean framework at all scales. The observed geometrical complexity appears to be largely a relict structure reflecting the superposition of many deformation phases in a long convoluted history. Structural complexity is generated primarily during initial deformation phases associated with strain hardening and low-slip organization phenomena that precede localization at various scales. Localization of deformation at a given scale is accompanied by a transition at that scale from strain hardening to weakening. Continuing slip leads to overall progressive structural regularization at the different scales.

Table 1 summarizes the evolution toward geometrical simplicity at four specific hierarchies. At scales of less than about $10 \mathrm{~m}$ representing internal fault zone structure, regularization of geometrical incompatibilities on the fault surface with progressive slip produces a tabular zone of granular rock that becomes fault gouge. Initially, shear deformation of the granular gouge zone is mostly accommodated by crushing particles, which is a hardening phenomenon and thus distributed across the layer. However, relatively small deformation leads to the development of a band-limited fractal distribution of grain sizes that suppresses further grain crushing and favors shear localization. The initial localization may be followed by several transient phases of delocalization, however the end result is localization onto a single surface within the gouge zone parallel to the direction of shear. Once this primary slip surface forms, the fractal granularity and oblique Riedel shear structures do not appear to play a significant role in subsequent slip. There is no evidence for persisting fluctuations between localized and delocalized deformation necessary to maintain active deformation on the entire fractal and/or granular structures.

A related evolution toward simplicity with increasing slip occurs on single fracture surfaces at scales on the order of a few $\mathrm{cm}$ or less. Fresh fractures with little or no slip have fractal surface roughness over broad ranges of scales. Often these are tensile fractures that are reactivated in shear, or shear fractures formed by the coalescence of many smaller shear fractures. With subsequent slip the surfaces 

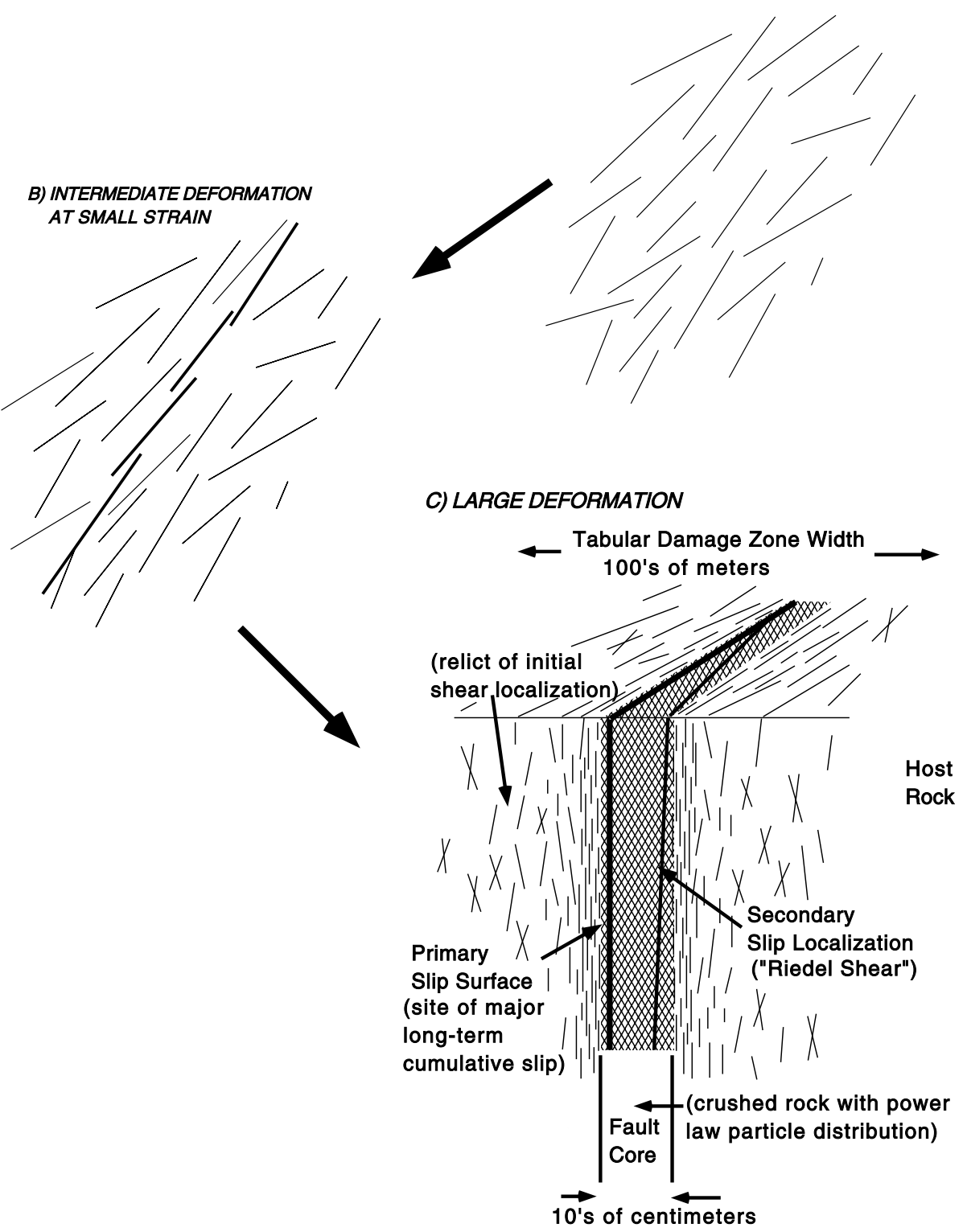

Figure 9

A conceptual representation of fault structures at three main evolutionary stages. (A) Initial deformation is associated with strain hardening. At this stage there is creation of granularity and band-limited fractal structures at several hierarchies. (B) After a relatively small initial strain there is localization to tabular primary slip zones accompanied by a transition to strain weakening. (C) Large deformation is dominated by strain weakening and overall evolution at different scales toward Euclidean geometry and progressive geometrical simplicity and regularization. The initial complex structure becomes largely passive at this stage. 
Table 1

The Geometrical, Mechanical, and Mathematical (GMM) mode of deformation evolves at different scales from (1) to (2) to (3) with progressive slip

\begin{tabular}{cccc}
\hline Dominant GMM Mode $\Rightarrow$ & Granular & Fractal & $\begin{array}{c}\text { Continuum- } \\
\text { Euclidean }\end{array}$ \\
\hline SCALE $\Downarrow$ & & & \\
Fracture Surface $(<1 \mathrm{~cm})$ & & $(1)$ & $(2)$ \\
Gouge Zone $(<10 \mathrm{~m})$ & $(1)$ & $(1)$ & $(3)$ \\
Fault System $(>1 \mathrm{~km})$ & & $(2)$ & $(3)$ \\
\hline Fault Network "Plate Boundary" $(>100 \mathrm{~km})$ & $(1)$ & & \\
\hline
\end{tabular}

become more planar in the shear direction while becoming increasingly separated by a layer of crushed rock as discussed above. The same regularization of slip zone geometry can also be observed on a fault system at scales greater than one kilometer where jogs and bends in the fault zone are smoothed with increasing displacement. Finally, at plate boundary scales on the order of $100 \mathrm{~km}$ or more, a regional network of faults accommodates deformation. Whether such networks originate as shear localizations in a granular matrix of crustal blocks or by the nucleation, growth and interaction of individual fractures is not known. However, active seismicity does not appear to populate the entire network, but is rather limited to a lower dimension subset. Again, the implication is that the active elements of the network are evolving toward a simpler more Euclidean structure.

The results suggest that long-term accommodation of crustal deformation may be described to first order by the continuum-Euclidean framework. Episodes of hardening and distributed deformation may be triggered by geometrical incompatibility associated with bends, jogs, and growth of individual faults, or the finite strain rotation of Euclidean structures to unfavorable orientations. However, these are transient perturbations on an irreversible trend toward overall progressive weakening and geometrical simplicity. The ubiquitous observation of complex seismicity patterns is often interpreted as evidence for a correspondingly complex structure. However, modeling studies have found that strong geometrical and material heterogeneity on an ensemble of planar faults can produce complex spatio-temporal patterns of seismicity including fractal distributions, spatio-temporal clustering, repeating earthquakes, linear streaks of microearthquakes, and other observed features.

In many situations deformation is accommodated by (or partitioned among) several sets of active faults with different orientations. Prominent examples include transition zones between different tectonic domains (e.g., the western North Anatolian fault near the sea of Marmara and the southern San Andreas fault near the Salton sea), areas near large bends of faults (e.g., the Los Angeles basin), and places where different sets of faults are juxtaposed as a result of slip on other faults. These examples and others exhibit high apparent complexity manifested by 
a diversity of fault types and earthquake focal mechanisms. Such complexity, however, can still be modeled by a collection of Euclidean surfaces and zones in a continuum matrix, as is done for example in routine seismological derivation of fault plane solutions. The regularization processes summarized by Figure 9 and Table 1 should be understood in such situations as operating separately on each active set.

We note that while our focus here is on mechanics, structural properties of faults are important to a variety of other issues including fluid flow in the crust and propagation of seismic waves. In these applications the relative importance of various structures is essentially the reverse of that for the mechanics discussed above. The crushed gouge zone and shattered wall rock, which are relict structures from the mechanical point of view, are the controlling structures for permeability and seismic velocity. The primary shear surfaces, which appear to dominate the mechanics of all but the most immature faults, play little role in determining properties of seismic waves. However, the damage zones around the primary shear localizations can guide seismic waves, and the complex crack population in the bulk controls the velocity, attenuation and scattering of seismic waves in the crust. From the hydrological point of view, the gouge and shattered wall rock provide a conduit for fluid flow in the crust. However, the primary shear localization and core ultracataclasite layer, which are the main carriers of slip, create a barrier to flow normal to the fault zone.

The main result of our review of current information on the geometrical, mechanical, and mathematical properties of fault zones is that strain weakening, geometrical simplicity, and continuum-based description provide a long-term attractor for structural evolution at all scales. This gives an organizing principle that may be used to integrate the diverse and often conflicting reports on fault zone properties. Since fault zones at seismogenic depths are not accessible for direct observation, the available information on their character is still coarse and sparse. A better understanding of the GMM character of fault zones will require additional geological and geophysical studies employing high-resolution high-penetration techniques.

\section{Acknowledgments}

We thank Fred Chester and Yan Kagan for discussions. The manuscript benefited from comments by Geoff King, Chris Marone, Steve Martel, and Judith Sheridan. The studies were supported by the National Science Foundation (grants EAR-9725358 (YBZ), EAR-9903049 (YBZ) and EAR-9902901 (CGS)) and the Southern California Earthquake Center (based on NSF Cooperative Agreement EAR-8920136 and USGS Cooperative Agreement 14-08-0001-A0899). 


\section{REFERENCES}

Adams, G. G. (1995), Self-excited Oscillations of Two Elastic Half Spaces Sliding with Constant Coefficient of Friction, J. Appl. Mech. 62, 867-872.

AKI, K. and LeE, W. H. K. (1976), Determination of Three-dimensional Velocity Anomalies under a Seismic Array Using First P Arrival Times from Local Earthquakes. 1. A Homogenous Initial Model, J. Geophys. Res. 81, 4381-4399.

Aki, K. and Richards, P. G. Quantitative Seismology: Theory and Methods. (W. H. Freeman, San Francisco, California (1980)).

An, L-J. and Sammis, C. G. (1994), Particle Size Distribution of Cataclastic Fault Materials from Southern California, Pure Appl. Geophys. 143, 203-227.

An, L-J. and SAmmis, C. G. (1996), A Cellular Automaton for the Development of Crustal Shear Zones, Tectonophysics 253, 247-270.

Andrews, D. J. (1980), A Stochastic Fault Model 1. Static Case, J. Geophys. Res. 85, 3867-3877.

Andrews, D. J. (1981), A Stochastic Fault Model 2. Time-dependent Case, J. Geophys. Res. 86, 10,82110,834 .

Andrews, D. J. (1989), Mechanics of Fault Junctions, J. Geophys. Res. 94, 9389-9397.

Andrews, D. J. and Ben-Zion, Y. (1997), Wrinkle-like Slip Pulse on a Fault Between Different Materials, J. Geophys. Res. 102, 553-571.

Arboleya, M. L. and Engelder, T. (1995), Concentrated Slip Zones with Subsidiary Shears: Their Development on Three Scales in the Cerro Brass Fault Zone, Appalachian Valley and Ridge, J. Structural Geol. 17, 519-532.

Aviles, C. A., Scholz, C. H., and BoAtwright, J. (1987), Fractal Analysis Applied to Characteristic Segments of the San Andreas Fault, J. Geophys. Res. 92, 331-344.

Aydin, A. and Johnson, A. M. (1978), Development of Faults as Zones of Deformation Bands and as Slip Surfaces in Sandstone, Pure Appl. Geophys. 116, 931-942.

Aydin, A. and Johnson, A. M. (1983), Analysis of Faulting in Porous Sandstones, J. Structural Geol. 5, 1931.

Beeler, N. M., Lockner, D. L., and Hickman, S. H. (2001), A Simple Stick-slip and Creep-slip Model for Repeating Earthquakes and its Implication for Micro-earthquakes at Parkfield, Bull. Seismol. Soc. Am., 91, 1797-1804.

BEn-Zion, Y. (1996), Stress, Slip and Earthquakes in Models of Complex Single-fault Systems Incorporating Brittle and Creep Deformations, J. Geophys. Res. 101, 5677-5706.

Ben-Zion, Y. (1998), Properties of Seismic Fault Zone Waves and their Utility for Imaging Low Velocity Structures, J. Geophys. Res. 103, 12,567-12,585.

Ben-Zion, Y. (2001), Recent Results on Dynamic Rupture in Earthquake Fault Models, J. Mech. Phys. Solids 49, 2209-2244.

Ben-Zion, Y. and Andrews, D. J. (1998), Properties and Implications of Dynamic Rupture Along a Material Interface, Bull. Seismol., Soc. Am. 88, 1085-1094.

Ben-Zion, Y., Dahmen, K., Lyakhovsky, V., Ertas, D., and Agnon, A. (1999), Self-driven Mode Switching of Earthquake Activity on a Fault System, Earth Planet. Sci. Lett. 172, 11-21.

Ben-Zion, Y., Katz, S., and Leary, P. (1992), Joint Inversion of Fault Zone Head Waves and Direct P Arrivals for Crustal Structure near Major Faults, J. Geophys. Res. 97, 1943-1951.

Ben-Zion, Y. and Malin, P. (1991), San Andreas Fault Zone Head Waves near Parkfield, California, Science 251, 1592-1594.

Ben-Zion, Y., Okaya, D., Peng, Z., Michael, A. J., Seeber, L., Armbruster, J. G., Ozer, N., Baris, S., and Aktar, M. (2000), High Resolution Imaging of the Geometry and Seismic Properties of the Karadere-Duzce Branch of the North Anatolian Fault at Depth, EOS Trans. Amer. Geophys. Union 81, F1172.

Ben-Zion, Y. and Rice, J. R. (1993), Earthquake Failure Sequences along a Cellular Fault Zone in a Threedimensional Elastic Solid Containing Asperity and Nonasperity Regions, J. Geophys. Res. 98, 14,109$14,131$.

Ben-Zion, Y. and Rice, J. R. (1995), Slip Patterns and Earthquake Populations along Different Classes of Faults in Elastic Solids, J. Geophys. Res. 100, 12,959-12,983. 
Biegel, R. L., Sammis, C. G., and Dieterich, J. H. (1989), The Frictional Properties of a Simulated Gouge Having a Fractal Particle Distribution, J. Structural Geol. 11, 827-846.

Bour, O. and Davy, P. (1999), Clustering and Size Distributions of Fault Patterns: Theory and Measurements, Geophys. Res. Lett. 26, 2001-2004.

Brown, S. R. (1995), Simple Mathematical Models of Rough Fracture, J. Geophys. Res. 100, 59415952.

Bruhn, R. L., Parry, W. T., Yonkee, W. A., and Thompson, T. (1994), Fracturing and Hydrothermal Alteration in Normal Fault Zones, Pure Appl. Geophys. 142, 609-644.

Brune, J. N., Brown, S., and Johnson, P. A. (1993), Rupture Mechanism and Interface Separation in Foam Rubber Model of Earthquakes: A Possible Solution to the Heat Flow Paradox and the Paradox of Large Overthrusts, Tectonophysics 218, 59-67.

Burgmann, R., Rosen, P. A., and Fielding, E. J. (2000), Synthetic Aperature Radar Interferometry to Measure Earth's Surface Topography and its Deformation, Ann. Rev. Earth and Plan. Sci. 28,169209.

Chester, F. M. and Logan, J. M. (1986), Implications for Mechanical Properties of Brittle Faults from Observations of the Punchbowl Fault Zone, California, Pure Appl. Geophys. 124, 79-106.

Chester, F. M. and Logan, J. M. (1987), Composite Planar Fabric of Gouge from the Punchbowl Fault, California, J. Structural Geol. 9, 621-634.

Chester, F. M., Evans, J. P., and Biegel, R. L. (1993), Internal Structure and Weakening Mechanisms of the San Andreas Fault, J. Geophys. Res. 98, 771-786.

Chester, F. M. and Chester, J. S. (1998), Ultracataclasite Structure and Friction Processes of the Punchbowl Fault, San Andreas System, California, Tectonophysics 295 199-221.

Chester, F. M. and Kirschner, D. L. (2000), Geochemical Investigation of Fluid Involvement in Exhumed Faults of the San Andreas System, National Earthquake Hazards Reduction Program, Annual Project Summary, 41, U.S. Geological Survey.

Dahmen, K., Ertas, D., and Ben-Zion, Y. (1998), Gutenberg Richter and Characteristic Earthquake Behavior in Simple Mean-Field Models of Heterogeneous Faults, Phys. Rev. E 58, 1494-1501.

Dieterich, J. H., A Model for the Nucleation of Earthquake Slip. In Earthquake Source Mechanics. AGU Geophys. Mono. 37. (Washington, D.C., American Geophysical Union 1986) pp. 37-49.

Dieterich, J. (1994), A Constitutive Law for Rate of Earthquake Production and its Application to Earthquake Clustering, J. Geophys. Res. 99, 2601-2618.

Dodge, D., Beroza, G. C., and Ellsworth, W. L. (1995), Evolution of the 1992 Landers, California, Foreshock Sequence and its Implications for Earthquake Nucleation, J. Geophys. Res. 100, 9865-9880.

Eberhart-Phillips, D. and Michael, A. J. (1993), Three-dimensional Velocity, Structure, Seismicity, and Fault Structure in the Parkfield Region, Central California, J. Geophys. Res. 98, 15,737-15,757.

Eberhart-Phillips, D. and Michael, A. J. (1998), Seismotectonics of the Loma Prieta, California, Region Determined from Three-dimensional $V_{p}, V_{p} / V_{s}$, and Seismicity, J. Geophys. Res. 103, 21,09921,120 .

Eberhart-Phillips, D., Stanley, W. D., Rodriguez, B. D., and Lutter, W. J. (1995), Surface Seismic and Electrical Methods to Detect Fluids Related to Faulting, J. Geophys. Res. 97, 12,91912,936 .

Evans, J. P. and Chester, F. M. (1995), Fluid-rock Interaction in Faults of the San Andreas System: Inferences from San Gabriel Fault Rock Geochemistry and Microstructures, J. Geophys. Res. 100, $13,007-13,020$.

Evans, J. P., Shipton, Z. K., Pachell, M. A., Lim, S. J., and Robeson, K. (2000), The Structure and Composition of Exhumed Faults, and their Implication for Seismic Processes, In Proc. of the $3^{\text {rd }}$ Confer. on Tecto. problems of the San Andreas system, Stanford University.

Feng, R. and McEvilly, T. V. (1983), Interpretation of Seismic Reflection Profiling Data for the Structure of the San Andreas Fault Zone, Bull. Seismol. Soc. Amer. 73, 1701-1720.

Fisher, D. S., Dahmen, K., Ramanathan, S., and Ben-Zion, Y. (1997), Statistics of Earthquakes in Simple Models of Heterogeneous Faults, Phys. Rev. Lett. 78, 4885-4888.

Freund, R. (1974), Kinematics of Transform and Transcurrent Faults, Tectonophysics 21, 93-134. 
Fuis, G. S. and Mooney, W. D. (1990), Lithospheric Structure and Tectonics from Seismic-Refraction and other data. In The San Andreas Fault System, California (ed. R. E. Wallace) U.S. Geol. Surv. Prof. Pap. 1515, 207-238.

Fukao, Y., Hori, S., and Ukawa, M. (1983), A Seismological Constraint on the Depth of Basalt-Eclogite Transition in a Subducting Oceanic Crust, Nature 303, 413-415.

Fung, Y. C., A First Course in Continuum Mechanics (2nd edition) (Prentice-Hall, Inc., New Jersey. 1977).

Gallagher, J. J., Jr. (1981), Tectonics of China: Continental Style Cataclastic Flow, in Mechanical Behavior of Crustal Rocks; The Handin Volume, Geophysical Monograph 24, pp. 259-273, American Geophysical Union, Washington, D.C.

Got, J.-L., Fréchet, J., and Klein, F. W. (1994), Deep Fault Plane Geometry Inferred from Multiplet Relative Relocation Beneath the South Flank of Kilauea, J. Geophys. Res. 99, 15,375-15,386.

Harris, R. A (1998), Introduction to Special Section: Stress Triggers, Stress Shadows, and Implications for Seismic Hazard, J. Geophys. Res. 103, 24,347-24,358.

Harris, R. A. and DAy, S. M. (1993), Dynamics of Fault Interactions: Parallel Strike-slip Faults, J. Geophys. Res. 98, 4461-4472.

Harris, R. A. and Simpson, R. W. (1996), In the Shadow of 1857-the Effect of the Great Ft. Tejon Earthquake on Subsequent Earthquakes in Southern California, Geophys. Res. Lett. 23, 229-232.

Heaton, T. H. (1990), Evidence for and Implications of Self-healing Pulses of Slip in Earthquake Rupture, Phys. Earth and Plan. Interiors 64, 1-20.

Herrero, A. and Bernard, P. (1994), A Kinematic Self-similar Rupture Process for Earthquakes, Bull. Seismol. Soc. Am. 84, 1216-1228.

Hirata, T. (1989), Fractal Dimension of Fault Systems in Japan: Fractal Structure in Rock Fracture Geometry at Various Scales, Pure Appl. Geophys. 131, 157-170.

Hough, S. E., Ben-Zion, Y., and LeAry, P. (1994), Fault-zone Waves Observed at the Southern Joshua Tree Earthquake Rupture Zone, Bull. Seismol. Soc. Am., 84, 761-767.

Ito, A. (1985), High Resolution Relative Hypocenters of Similar Earthquakes by Cross-spectral Analysis Method, J. Phys. Earth 33, 279-294.

Jaeger, M., Nagel, S. R., and Behringer, R. P. (1996), Granular Solids, Liquids, and Gases, Rev. of Mod. Phys. 68, 1259-1273.

Kagan, Y. Y. (1981a), Spatial Distribution of Earthquakes: The Tree-point Moment Function, Geophys. J. R. Astron. Soc. 67, 697-717.

Kagan, Y. Y. (1981b), Spatial Distribution of Earthquakes: The Four-point Moment Function, Geophys. J. R. Astron. Soc. 67, 719-733.

Kagan, Y. Y. (1991), Fractal Dimension of Brittle Fracture, J. Nonlinear Sci. 1, 1-16.

Kagan, Y. Y. (1992), Seismicity: Turbulence of Solids, Nonlinear Sci. Today 2, 1-13.

KaGAN, Y. Y. (1994), Observational Evidence for Earthquakes as a Nonlinear Dynamic Process, Physica D $77,160-192$.

Kagan, Y. Y. and Knopoff, L. (1980), Spatial Distribution of Earthquakes: The Two-point Correlation Function, Geophys. J. R. Astron. Soc. 62, 303-320.

Keilis-Borok, V. I. and Kossobokov, V. G. (1990), Premonitory Activation of Earthquake Flow: Algorithm M8, Phys. Earth Planet. Inter. 61, 73-83.

KInG, G. C. P. (1983), The Accommodation of Large Strains in the Upper Lithosphere of the Earth and Other Solids by Self-similar Fault Systems: The Geometrical Origin of b-value, Pure Appl. Geophys., 121, 761-814.

KING, G. C. P. and Cocco, M. (2001), Fault Interaction by Elastic Stress Changes: New Clues from Earthquake Sequences, Adv. in Geophys. 44, 1-38.

Kuwahara, Y. and Ito, H. (2000), Deep Structure of the Nojima Fault by Trapped Wave Analysis, USGS, Open-file Report 00-129, 283-289.

LEARY, P. C. (1991), Deep bore hole log evidence for fractal distribution of fractures in crystalline rock, Geophys. J. Int., 107, 615-627.

Leary, P., Li, Y. G., and AKI, K. (1987), Observations and Modeling of Fault Zone Fracture Anisotropy, I, P, SV, SH Travel Times, Geophys. J. R. Astron. Soc. 91, 461-484.

Lees, J. and Malin, P. E. (1990), Tomographic Images of P-wave Velocity Variation at Parkfield, California, J. Geophys. Res. 95, 21,793-21,804. 
Li, Y. G., Aki, K., Adams, D., Hasemi, A., and Lee, W. H. K. (1994), Seismic Guided Waves Trapped in the Fault Zone of the Landers, California, Earthquake of 1992, J. Geophys. Res. 99, 11705-11722.

Li, Y. G., Aki, K., Vidale, J. E., and Alvarez, M. G. (1998), A Delineation of the Nojima Fault Ruptured in the M7.2 Kobe, Japan, Earthquake of 1995 Using Fault-zone Trapped Waves, J. Geophys. Res. 103, 7247-7263.

Li, Y. G., Ellsworth, W. L., Thurber, C. H., Malin, P. E., and Aki, K. (1997), Fault-zone Guided Waves from Explosions in the San Andreas Fault at Parkfield and Cienega Valley, Bull. Seismol. Soc. Am. $87,210-221$.

Li, Y. G., Leary, P., Aki, K., and Malin, P. (1990), Seismic Trapped Modes in the Oroville and San Andreas Fault Zones, Science 249, 763-766.

Lockner, D. (1998), A Generalized Law for Brittle Deformation of Westerly Granite, J. Geophys. Res. 103, 5107-5123.

Lockner, D. A., Byerlee, J. D., Kuksenko, V., Ponomarev, A., and Sidrin, A., Observations of Quasistatic Fault Growth from Acoustic Emissions. In Fault Mechanics and Transport Properties of Rocks (eds. B. Evans and T.-f. Wong) pp. 3-31 (Academic, San Diego, Calif. 1992).

Luyendyk, B. P. (1991), A Model of Neogene Crustal Rotations, Transtension, and Transpression in Southern California, Geol. Soc. Am. Bull. 103, 1528-1536.

Lyakhovsky, V., Ben-Zion, Y., and Agnon, A. (1997), Distributed Damage, Faulting, and Friction, J. Geophys. Res. 102, 27,635-27,649.

Lyakhovsky, V., Ben-Zion, Y., and Agnon, A. (2001), Earthquake Cycle Faults, and Seismicity Patterns in Rheologically Layered Lithosphere, J. Geophys. Res. 106, 4103-4120.

Mackie, R. L., Livelybrooks, D. W., Madden, T. R., and Larsen, J. C. (1997), A Magnetotelluric Investigation of the San Andreas Fault at Carrizo Plain California, Geophys. Res. Lett. 24, 18471850 .

Mandelbrot, B. B. (1983), The Fractal Geometry of Nature ( $3^{\text {rd }}$ edition) (W. H. Freeman and Company, New York).

Marco, S., Stein, M., Agnon, A., and Ron, H. (1996), Long-term Earthquake Clustering: A 50,000 Year Paleoseismic Record in the Dead Sea Graben, J. Geophys. Res. 101, 6179-6192.

Marone, C. and Kilgore, B. (1993), Scaling of the Critical Slip Distance for Seismic Faulting with Shear Strain in Fault Zones, Nature, 362, 618-21.

Marone, C. and Scholz, C.H. (1989), Particle-size Distribution and Microstructures within Simulated Fault Gouge, J. Struct. Geology 11, 799-814.

Martel, S. J. (1990), Formation of Compound Strike-slip Fault Zones, Mount Abbot Quadrangle, California, J. Struct. Geol. 12, 869-881.

Martel, S. J., Pollard, D. D., and Segall, P. (1988), Development of Simple Fault Zones in Granitic Rock, Mount Abbot Quadrangle, Sierra Nevada, California, Geol. Soc. of Am. Bull. 100, 14511465 .

McGuire, J. J., Zhao, L., and Jordan, T. H. (2000), Predominance of Unilateral Rupture for a Global Distribution of Large Earthquakes, EOS Trans. Am. Geophs. Union 81, F1228.

Michael, A. J. and Ben-ZIon, Y. (2002), Determination of Fault Zone Structure from Seismic Guided Waves by Genetic Inversion Algorithm and 2-D Analytical Solution: Application to the Parkfield Segment of the San Andreas Fault, ms. in preparation.

Michael, A. J. and Eberhart-Phillips, D. (1991), Relations Among Fault Behavior, Subsurface Geology, and Three-dimensional Velocity Models, Science 253, 651-654.

Michelini, A. and McEvilly, T. V. (1991), Seismological Studies at Parkfield, I, Simultaneous Inversion for Velocity Structure and Hypocenters Using Cubic B-spline Parameterization, Bull. Seismol. Soc. Am. 81, $524-552$.

Mooney, W. D. and Brocher, T. M. (1987), Coincident Seismic Reflection/Refraction Studies of Continental Lithosphere: A Global Review, Rev. Geophys. 25, 723-742.

Mooney, W. D. (1989), Seismic Methods for Determining Earthquake Source Parameters and Lithospheric Structure, Mem. Geol. Soc. Am. 172, 11-34.

Neal, L. A., Chester, J. S., Chester, F. M., and Wintsch, R. P. (2000), Internal Structure of the Kern Canyon Fault, California: A Deeply Exhumed Strike-slip Fault, EOS Trans. Am. Geophys. Union 81, F1145. 
Nadeau, R., Antolik, M., Johnson, P. A., Foxall, W., and McEvilly, T. V. (1994), Seismological Studies at Parkfield III: Microearthquake Clusters in the Study of Fault-zone Dynamics, Bull. Seismol. Soc. Am. 84, 1247-263.

Nadeau, R. M. and Johnson, L. R. (1998), Seismological Studies at Parkfield VI: Moment Release Rates and Estimates of Source Parameters for Small Repeating Earthquakes, Bull. Seismol. Soc. Am. 88, 790-814.

Nadeau, R. M. and McEvilly, T. V. (1997), Seismological Studies at Parkfield V: Characteristic Microearthquake Sequences as Fault-zone Drilling Targets, Bull. Seismol. Soc. Am. 87, 1463-1472.

Nalbant, S., Hubert, A., and King, G. C. P. (1998), Stress Coupling in North West Turkey and the North Aegean, J. Geophys. Res. 103, B10, 24,469-24,486.

Nishigami, K., Ando, M., and Tadokoro, K. (2001), Seismic Observations in the DPRI $1800 \mathrm{~m}$ Borehole Drilled into the Nojima Fault Zone, Southwest Japan, Island Arc, 10, 288-295.

Nur, A., Ron, H., and ScotTi, O. (1989), Kinematics and Mechanics of Tectonic Block Rotations, Geophys. Mono. 49, 31-46.

Oкuво, P. G. and Aкi, K. (1987), Fractal Geometry in the San Andreas Fault System, J. Geophys. Res. 92, 345-355.

Ouillon, G., Castaing, C., and Sornette, D. (1996), Hierarchical Geometry of Faulting, J. Geophys. Res. 101, 5477-5487.

Peng, Z., Ben-Zion, Y., and Michael, A. J. (2000), Inversion of Seismic Fault Zone Waves in the Rupture Zone of the 1992 Landers Earthquake for High Resolution Velocity Structure at Depth, EOS Trans. Am. Geophys. Union 81, F1146.

Power, W. L. and Tullis, T. E. (1991), Euclidean and Fractal Models for the Description of Rock Surface Roughness, J. Geophys. Res. 96, 415-424.

Power, W. L., Tullis, T. E., and Weeks, J. D. (1988), Roughness and Wear During Brittle Faulting, J. Geophys. Res. 93, 15,268-15,278.

Prasher, C., Crushing and Grinding Process Handbook (John Wiley and Sons Ltd., New York. 1987).

Rice, J. R. (1993), Spatio-temporal Complicity of slip on a fault, J. Geophys. Res., 98, 9885-9907.

Richards-Dinger, K. B. and Shearer, P. M. (2000), Earthquake Locations in Southern California Obtained Using Source-specific Station Terms, J. Geophys. Res. 105, 10,939-10,960.

Robertson, M. C., Sammis, C. G., Sahimi, M., and Martin, A. (1995), The 3-D spatial Distribution of Earthquakes in Southern California with a Percolation Theory Interpretation, J. Geophys. Res. 100, 609620.

Rockwell, T. K., Lindvall, S., Herzberg, M., Murbach, D., Dawson, T., and Berger, G. (2000), Paleoseismology of the Johnson Valley, Kickcapoo and Homestead Valley Faults of the Eastern California Shear Zone, Bull. Seismol. Soc. Am. 90, 1200-1236.

Rubin, A. M. and Gillard, D. (2000), Aftershock Asymmetry/Rupture Directivity Among Central San Andreas Fault Microearthquakes, J. Geophys. Res. 105, 19,095-19,109.

Rubin, A. M., Gillard, D., and Got, J.-L. (1999), Streaks of Microearthquakes along Creeping Faults, Nature 400, 635-641.

Sammis, C. G., Nadeau, R. M., and Johnson, L. R. (1999), How Strong is an asperity?, J. Geophys. Res. 104, 10,609-10,619.

Sammis, C. G., An, L. and Ershaghi, I. (1992), Determining the 3-D Fracture Structure of the Geysers Geothermal Reservoir, Proc. $17^{\text {th }}$ Workshop on Geothermal Reservoir Engineering, Stanford University, Stanford, CA, Jan. 29-31.

Sammis, C. G. and Biegel, R. (1989), Fractals, Fault-gouge, and Friction, Pure Appl. Geophys. 131, 255271.

Sammis, C. G. and Steacy, S. J. (1994), The Micromechanics of Friction in a Granular Layer, Pure Appl. Geophys. 142, 777-794.

Sammis, C. G., King, G. C. P. and Biegel, R. (1987), The Kinematics of Gouge Deformation, Pure Appl. Geophys. 125, 777-812.

SAmmis, C. G. and Rice, J. R. (2001), Repeating Earthquakes as Low-stress-drop Events at a Border between Locked and Creeping Fault Patches, Bull. Seismol. Soc. Am., 91, 532-537.

Scholz, C. H. (1991), Earthquakes and faulting: Self-organized critical phenomena with a characteristic dimension. In Spontaneous Formation of Space-time Structures and Criticality (eds. T. Riste and D. Sherrington) (Kluwer Acad., Norwell, Mass.) pp. 41-56. 
Schulz, S. E. and Evans, J. P. (2000), Mesoscopic Structure of the Punchbowl Fault, Southern California and the Geologic and Geophysical Structure of Active Strike-slip Faults, J. of Struct. Geol. 22, 913-930.

Segall, P. and Davis, J. L. (1997), GPS Applications for Geodynamics and Earthquake Studies, Ann. Re. Earth and Planet. Sci. 25, 301-336.

Segall, P. and Pollard, D. D. (1983), Nucleation and Growth of Strike-slip Faults in Granite, J. Geophys. Res. $88,555-568$.

Shapiro, N. M., Campillo, M., Singh, S. K., and Pacheco, J. (1998), Seismic Channel Waves in the Accretionary Prism of the Middle America Trench, Geophys. Res. Lett. 25, 101-104.

SheArer, P. (1997), Improving Local Earthquake Locations Using the L1 Norm and Waveform Cross Correlation: Application to the Whittier Narrows, California, Aftershock Sequence, J. Geophys. Res. 102, 8269-8283.

Sibson, R. H. (1986), Brecciation Processes in Fault Zones: Inferences from Earthquake Rupturing, Pure Appl. Geophys. 124, 159-176.

Sibson, R. H. (1999), Thickness of the Seismogenic Slip Zone: Constraints from Field Geology, EOS Trans. Amer. Geophys. Union 80, F727.

Simpson, R. W. and Reasenberg, P. A. (1994), Earthquake-induced Static Stress Changes on Central California Faults. In the Loma Prieta, California earthquake of October 17, 1989-tectonic processes and models, (R. W. Simpson, ed.) U. S. Geological Survey Prof. Paper 1550-F.

Smith, J. T. and Booker, J. R. (1991), Rapid Inversion of Two- and Three-dimensional Magnetotelluric Data, J. Geophys. Res. 96, 3905-3922.

Steacy, S. J. and Sammis, C. G. (1991), An Automaton for Fractal Patterns of Fragmentation, Nature 353 , $250-252$.

Stein, R. S., Barka, A. A., and Dieterich, J. H. (1997), Progressive Failure on the North Anatolian Fault since 1939 by Earthquake Stress Triggering, Geophys. J. Int. 128, 594-604.

Stein, R. S., King, G., and Lin, J. (1994), Stress Triggering of the 1994 M-6.7 Northridge, California, Earthquake by its Predecessors, Science 265, 1432-1435.

Stierman, D. J. (1984), Geophysical and Geological Evidence for Fracturing, Water Circulation, and Chemical Alteration in Granitic Rocks Adjacent to Major Strike-slip Faults, J. Geophys. Res. 89, 58494857.

Stirling, M. W., Wesnousky, S. G., and Shimazaki, K. (1996), Fault Trace Complexity, Cumulative Slip, and the Shape of the Magnitude-frequency Distribution for Strike-slip Faults: a Global Survey, Geophys. J. Int. 124, 833-868.

Tchalenko, J. S. (1970), Similarities between Shear Zones of Different Magnitudes, Bull. Geol. Soc. Am. $81,1625-1640$.

Utsu T., Ogata, Y., and Matsu'ura, R. S. (1995), The Centenary of the Omori Formula for a Decay Law of Aftershock Activity, J. Phys. Earth 43, 1-33.

Unsworth, M., Egbert, G., and Booker, J. (1999), High-resolution Electromagnetic Imaging of the San Andreas Fault in Central California, J. Geophys. Res. 104, 1131-1150.

Wald, D. J. (1992), Rupture Characteristics of California Earthquakes, Ph.D. Thesis, Caltech.

Waldhauser, F., Ellsworth, W. L., and Cole, A. (1999), Slip-parallel Seismic Lineations Along the Northern Hayward Fault, California, Geophys. Res. Lett. 26, 3525-3528.

Wang, C. Y., Rui, F., Zhengsheng, Y., and Xinguue, S. (1986), Gravity Anomaly and Density Structure of the San Andreas Fault Zone, Pure Appl. Geophys. 124, 127-140.

Weertman, J. (1980), Unstable Slippage across a Fault that Separates Elastic Media of Different Elastic Constants, J. Geophys. Res. 85, 1455-1461.

WeSnousky, S. (1994), The Gutenberg-Richter or Characteristic Earthquake Distribution, which is it?, Bull. Seismol. Soc. Am. 84, 1940-1959.

Wesnousky, S. (1988), Seismological and Structural Evolution of Strike-slip Faults, Nature 335, 340342 .

Willemse, E. J. M., Peacock, D. C. P., and Aydin, A. (1997), Nucleation and Growth of Strike-slip Faults in Limestones from Somerset, U. K., J. Struct. Geol. 19, 1461-1477.

Zeng, Y., Anderson, J. G., and YU, G. (1994), A Composite Source Model for Computing Realistic Synthetic Strong Ground Motion, Geophys. Res. Lett. 21, 725-728. 
Zhu, L. and Helmberger, D. V. (1996), Advancement in Source Estimation Techniques Using Broadband Regional Seismograms, Bull. Seismol. Soc. Am. 86, 1634-1641.

(Received, November 2, 2000, accepted April 6, 2001)

(17) To access this journal online:

IDP http://www.birkhauser.ch 